\title{
Financial market misconduct and public enforcement: The case of Libor manipulation
}

\author{
Priyank Gandhi, Benjamin Golez, Jens Carsten Jackwerth, and Alberto Plazzi*
}

This Version: February 10, 2016

\begin{abstract}
What is the role of public enforcement in preventing widespread financial market misconduct? We study this question using the events surrounding the manipulation of the London Interbank Offer Rate (Libor). We find pervasive evidence consistent with banks misreporting Libor submissions to profit from Libor-related positions in the full sample 1999-2012. The evidence is initially stronger for banks incorporated outside the U.S., where enforcement is historically weaker, and it disappears in the aftermath of Libor investigations. Overall, our results suggest that improvements in public enforcement can be effective in deterring financial market misconduct.
\end{abstract}

Keywords: Libor, manipulation, financial market misconduct, enforcement JEL classification: G11, G12, K42

\footnotetext{
*Gandhi: Mendoza College of Business, University of Notre Dame, Notre Dame, IN 46556, USA, Tel.: +1-574-6313450, pgandhi@nd.edu. Golez: Corresponding author. Mendoza College of Business, University of Notre Dame, Notre Dame, IN 46556, USA, Tel.: +1-574-631-1458, Fax.: +1-574-631-5255, bgolez@nd.edu. Jackwerth: University of Konstanz, PO Box 134, 78457 Konstanz, Germany, Tel.: +49-(0)7531-88-2196, jens.jackwerth@uni-konstanz.de. Plazzi: University of Lugano and Swiss Finance Institute, Via Buffi 13 Lugano, 6900, Switzerland, Tel.: +41-(0)58-666-4677, alberto.plazzi@usi.ch.

We would like to thank Viral Acharya, Patrick Augustin (discussant), Utpal Bhattacharya, Anna Cieslak, George Constantinidies, Shane Corwin, Guenter Franke, Francesco Franzoni, Corey Garriott (discussant), Thorsten Hens, Kostas Iordanidis, Winfried Pohlmeier, Veronika Pool (discussant), Rossen Valkanov, and seminar participants at the BI Norwegian Business School, Carlos III in Madrid, the University of Konstanz, University of Notre Dame, the University of Zurich, Bank of Slovenia, 2013 State of Indiana Conference, 2014 Schulich School of Business Conference on Financial Market Misconduct, 2014 European Finance Association Conference, and 2015 SFS Finance Cavalcade for helpful comments. This paper has been previously circulated under the title 'Libor manipulation: Cui bono?'.
} 


\section{Introduction}

Recent banking scandals, such as the manipulation of the London Interbank Offer Rate (Libor) and the fixing of foreign exchange, have once again impaired trust in the financial markets. These cases of financial market misconduct are unprecedented in terms of the number of banks involved and the potential impact on the real economy. The regulators responded by large scale investigations and historically large penalties for the involved banks. However, it still remains a largely open question how effective are these measures. Is improved enforcement of existing regulations enough to prevent widespread financial market misconduct? ${ }^{1}$ How does financial market misconduct vary across countries with different enforcement intensity? Are the imposed penalties sufficient to outweigh the potential gains from misconduct?

In this paper, we tackle these questions by analyzing the events surrounding the manipulation of Libor. We start by a comprehensive analysis of the extent and the main driving forces of Libor manipulation. Then we use differences in enforcement intensity over time and across regulatory regimes to assess the effect of enforcement intensity on the propensity to engage in Libor manipulation.

Libor was introduced by the British Banking Association (BBA) in 1986 as a measure of the inter-bank borrowing rate and is now a crucial reference rate for spot and derivative contracts with notional value of several hundred trillion dollars. The allegations of Libor manipulation started with a 2008 Wall Street Journal article (Mollenkamp and Whitehouse (2008)) and eventually led to widespread investigations into Libor manipulation. Nine large international banks have already reached settlement agreements with regulators, and several banks are still under investigation. $^{2}$

The case of Libor manipulation provides a unique opportunity to study the effects of enforcement on the propensity of market participants to engage in financial market misconduct for three reasons. First, while regulators launched formal investigations soon after the first allegation of Libor manipulation, no changes were implemented in the way Libor is computed until

\footnotetext{
${ }^{1}$ For corporate fraud, Dyck, Morse, and Zingales (2014) argue that only one quarter of cases are detected and on average one out of seven large publicly-traded US firms are engaged in fraud.

${ }^{2}$ The first bank to reach a settlement agreement with the regulators was Barclays Bank in June 2012. The penalties imposed on banks as of July 2015 are: Deutsche Bank $\$ 2.5$ billion, Union Bank of Switzerland $\$ 1.52$ billion, Royal Bank of Scotland $\$ 1.14$ billion, Rabobank $\$ 1.07$ billion, Societe Generale $\$ 605$ million, Barclays Bank $\$ 454$ million, Lloyds Bank $\$ 370$ million, J.P. Morgan $\$ 108$ million, and Citigroup $\$ 95$ million.
} 
2013, when the administration of Libor was transferred from the BBA to the ICE Benchmark Administration (IBA). ${ }^{3}$ Thus, by focusing on the period before 2013, we can isolate the effect of the enforcement actions on banks' incentives to manipulate Libor from other regulatory changes in the procedure followed to compute Libor. This is difficult in other instances because increased enforcement intensity is often accompanied by changes in regulations. For example, the Global Settlement Agreement from 2003 simultaneously imposed penalties and advocated changes to the rules related to investment banks' analysts. Second, the Libor manipulation involves several banks around the globe, which enables us to explore how cross-country differences in enforcement intensity affect banks' incentives to manipulate Libor. Third, penalties imposed by regulators on banks in relation to Libor manipulation are large, and we therefore expect them to have an important effect on the extent of Libor manipulation. In particular, the cumulative penalties for Libor manipulation amount to $\$ 8$ billion dollars, which is much larger than any of the fines previously imposed on financial institutions other than the recent penalties related to the foreign exchange rate manipulations. ${ }^{4}$

Theoretically, the propensity to engage in financial market misconduct depends on the benefits and expected costs of these activities (Becker (1968)). Accordingly, our empirical approach unfolds as a cost-benefit analysis of Libor manipulation. We first explore banks' incentives to manipulate Libor and test for the presence of manipulation. Once we establish the exact channel for Libor manipulation, we then analyze how the evidence for manipulation varies with enforcement intensity.

In our sample period, Libor was computed by the BBA as a trimmed average of the selfreported borrowing costs (Libor submissions) of select groups of panel banks. ${ }^{5}$ Panel banks were obliged to report their true borrowing costs, but were not required to base submissions on actual transactions data. ${ }^{6}$ Although explicitly prohibited, the self-reported nature of Libor allowed banks to (partially) align their submissions with their own interests. The first allegations for Libor manipulation suggested that banks were underreporting their borrowing costs to appear less risky as compared to their peers (Mollenkamp and Whitehouse (2008)). We refer to this

\footnotetext{
${ }^{3}$ Details on Libor computation and reforms are provided in Section 3.

${ }^{4}$ Fines related to the Global Settlement Agreement amount to $\$ 1.4$ billion and the recently imposed penalties for fixing the foreign exchange rates are about $\$ 10$ billion.

${ }^{5}$ The number of reporting (panel) banks varies across different currencies from 6 (Swedish Krona) to 18 (U.S. Dollar).

${ }^{6}$ See http://www.bbatrent.com.
} 
motivation for manipulation as the "signaling hypothesis." Later, attention shifted to another, possibly more important, channel for Libor manipulation: banks aligning their submissions in the direction of their Libor exposure in an attempt to move Libor in the desired direction and profit from their Libor-related positions (Snider and Youle (2012)). We refer to this motivation for manipulation as the "cash flow hypothesis."

We test both hypotheses empirically in a two stage procedure. In the first stage, we estimate proxies for banks' incentives to manipulate Libor. In the second stage, we then test the signaling and the cash flow hypotheses by relating our proxies for incentives to manipulate Libor to banks' future Libor submissions.

To measure banks' incentives to manipulate Libor, we would ideally require high frequency data on Libor positions for all the banks in our sample. Unfortunately, such data do not exist because banks are not required to publicly release detailed information on their interest rate exposure. ${ }^{7}$ We therefore propose an alternative approach. We build on the premise that Libor manipulation would lead to increased valuations for the banks. Under the cash flow hypothesis, changes in Libor affect banks' valuations through increased cash flows from their Libor-related positions. Under the signaling hypothesis, changes in Libor submissions affect banks' valuations through changes in the perceived riskiness of banks. Following our premise, we then regress each bank's excess returns on changes in Libor and changes in bank's Libor submissions while controlling for bank's riskiness. We interpret the estimated coefficient on changes in Libor as a proxy for incentives to manipulate Libor due to the cash flow hypothesis and the estimated coefficient on changes in Libor submissions as a proxy for incentives to manipulate Libor due to the signaling hypothesis. To account for time-series variation, we use a rolling window approach.

This technique is similar in spirit to the style analysis used in the asset management applications and resembles a common approach to estimating interest rate exposure in the banking literature (see Flannery and James (1984) and Acharya and Steffen (2015)). We provide a number of tests to validate our empirical approach. First, we document that our measure of a bank's Libor exposure varies with the amount of a bank's Libor denominated loans. In particular, when a bank issues a new syndicated loan, our measure of bank's Libor exposure increases. Second,

\footnotetext{
${ }_{7}^{7}$ Even the Call Reports (the most comprehensive source for banks' balance sheet data collected by the U.S. Federal Reserve) provide only incomplete information on interest rate exposures and only for a subset of banks in our sample that are FDIC insured. We cross-validate our methodology using these data in Section 7.
} 
for a subset of banks, for which a more detailed interest rate data exist, we show that our measure of bank's Libor exposure is correlated with a bank's Libor exposure estimated from balance sheet data. Third, we present a number of tests to show that our results cannot be explained by the differences in banks' general exposure to the interest rate risk. Finally, we show that our approach is robust to potential endogeneity in the estimation of the Libor sensitivities of banks.

We use data on Libor submissions from 1999 through 2012 from Bloomberg for the 12 most important Libor currency-maturity pairs as identified by Wheatley (2012). ${ }^{8}$ We find strong empirical evidence consistent with the cash flow hypothesis. In particular, in the full sample 1999-2012, banks' Libor exposures are positively and significantly related to banks' future Libor submissions. This is supportive of banks misreporting their Libor submissions to profit from their holdings of Libor-related products. A one standard deviation increase in the Libor exposure of a panel bank implies a 0.066 basis point increase in its average submission over the subsequent month. The magnitude is economically important; given the large notional value of contracts tied to Libor, even a fraction of a basis point can result in large cash flow transfers among investors. ${ }^{9}$ In line with the cash flow hypothesis, we also find that manipulation is more pronounced for the Libor rate with the largest notional value of interest rate derivatives outstanding.

In comparison, the evidence for the signaling hypothesis is weak and statistically insignificant. In particular, we find no association between banks's incentives for signaling and subsequent submissions, either in the full sample or in the subsamples where the incentives for signaling may be higher. This is consistent with the mixed evidence for the signaling hypothesis in studies that compare Libor submissions to alternative proxies for banks's borrowing costs (e.g., Abrantes-Metz, Kraten, Metz, and Seow (2012)).

Having established the main channel for Libor manipulation as the cash flow hypothesis, we next test how the evidence for Libor manipulation varies with enforcement intensity. Theoretically, enforcement affects the level of financial market misconduct by altering the expected legal costs of misconduct. The expected legal costs depend on the size of the potential penalties and the perceived probability of being discovered. These costs are therefore difficult to measure ex-ante (Becker (1968)). In the case of Libor manipulation, however, the passage of time and

\footnotetext{
${ }^{8}$ The USD, GBP, JPY, and CHF for the 1-, 3-, and 6-month maturities.

${ }^{9}$ Deutsche Bank calculated that, as of September 30, 2008, it could gain or lose as much as 68 million Euro per one basis point change in Libor (Eaglesham (2013)).
} 
the geographical distribution of banks are informative about the expected legal costs.

In the absence of clear monitoring of Libor submissions, the expected legal costs of manipulation were presumably low at the beginning of our sample, increasing rapidly as the investigations in Libor manipulation intensified. By 2011, when a Wall Street Journal article (Enrich, Mollenkamp, and Eaglesham (2011)) reported that regulators were investigating banks in their probe of Libor manipulation, it is safe to assume that all banks were aware of the increasing costs of manipulation. Indeed, we find that the evidence for manipulation is initially strong but disappears after 2010. ${ }^{10}$ Next, compared with the U.S., enforcement of regulation has historically been weaker in other countries (Coffee (2007)). Consistent with this argument, we find that manipulation is initially present only for banks incorporated outside of the U.S. Subsequently, the evidence for manipulation disappears for all banks, regardless of their country of incorporation.

To gain further insights into the costs and benefits of Libor manipulation, we next calculate the hypothetical Libor, which would have obtained if banks were not misreporting Libor submissions. Based on the difference between the actual Libor and the hypothetical Libor, we then estimate banks' gains from Libor manipulation. For the five banks that were penalized most severely, the estimated gains from manipulation in market capitalization are $\$ 13.9$ billion, which is approximately twice the size of penalties imposed by regulators on these banks ( $\$ 6.2$ billion cumulatively). Given that these fines exclude any reputational costs and costs related to civil lawsuits, our results suggest that the legal costs of manipulation turned out to be substantial, weighing importantly against the future benefits of manipulation.

Our results are robust to changes in the choice of control variables, the length of the rolling window in estimating proxies for incentives to manipulate Libor, the use of either weekly or monthly data, and the precise timing of Libor investigations. Importantly, results depend on the use of the signed Libor exposure as opposed to the magnitude of the Libor exposure, which suggests that our results are not driven by differences in banks' interest rate risk. Results are also robust to controlling for changes in other short term interest rates (T-bill) and estimating Libor exposure within an instrumental variable approach.

All in all, we document widespread evidence consistent with banks manipulating Libor to profit from their holdings of Libor-related products. We also show that the manipulation was

\footnotetext{
${ }^{10}$ Note that our sample ends before any changes in the Libor computation were introduced.
} 
initially present only for banks incorporated outside the U.S., where enforcement is historically weaker, and it disappeared in the aftermath of increased prosecutions by the regulators in 2010 . Our results therefore suggest that credible enforcement of existing regulations, along with the threat of large penalties, may be adequate to discipline financial market participants. Although our results are all based on the case of Libor manipulation, we expect them to have bearing on other cases of financial market misconduct, especially other large-scale banking scandals, such as foreign exchange fixing.

\section{Related literature}

Our paper relates to two streams of the literature - the studies on the cost-benefit analysis of financial market misconduct and the papers on Libor manipulation.

\subsection{Enforcement and incentives for financial market misconduct}

Motivated by the theory on law and economics (Becker (1968)), we analyze the extent of Libor manipulation through the lens of a cost-benefit analysis and show how the evidence for manipulation decreases with increased enforcement intensity, both over time and across regulatory regimes. In a similar vein, Kedia and Rajgopal (2011) find that firms located closer to the SEC (and more likely to be prosecuted by the SEC) are less likely to manipulate their financial statements.

Several related papers study the impact of enforcement on financial market misconduct indirectly by analyzing its impact on capital markets. For example, Bhattacharya and Daouk (2002) show that the cost of equity in a country decreases after the first prosecution of insider trading. Coffee (2007) argues that the higher enforcement intensity in the U.S. is related to the overall lower cost of capital in the U.S. In comparison, we show a direct connection between higher enforcement intensity in the U.S. and the lack of Libor manipulation by U.S. banks. Consistent with Bhattacharya and Daouk (2002), our results suggest that the existence of rules without effective enforcement is not enough to mitigate financial misconduct.

Our paper is also related to studies which analyze the combined effect of enforcement and regulatory changes on the behavior of market participants. For example, Madureira, Kadan, 
Wang, and Tzachi (2009) and Corwin, Larocque, and Stegemoller (2015) show that the Global Analyst Research Settlement in 2003 diminished conflicts of interest in sell-side research. Because the settlement imposed both penalties for the involved institutions and new rules on the interdependence between the banks' research and investment departments, however, it is difficult to disentangle the effect of enforcement and the effect of regulatory changes on behavior of financial institutions. In comparison, in the case of Libor manipulation, we can isolate the confounding effect of regulatory changes (by focusing on the time before 2013) and thus capture only the impact of increased enforcement intensity on the extent of Libor manipulation.

Finally, our paper is related to the literature on incentives for financial misreporting. Bergstresser and Philippon (2006) and Burns and Kedia (2006) show that performance-based compensation incentivizes managers to manipulate prices through misreporting, earnings management, and fraudulent accounting. Bollen and Pool (2009), Agarwal, Daniel, and Naik (2011) and BenDavid, Franzoni, Landier, and Moussawi (2013) show that incentive contracts drive hedge fund managers to misreport returns. Similarly, we argue that incentives for increased bank valuation (which subsequently determine management bonuses) may drive panel banks to misreport Libor submissions. Thereby we also add to the discussion on the unethical culture in corporations and in the financial industry (Biggerstaff, Cicero, and Puckett (2014) and Lo (2015)).

\subsection{Libor manipulation}

The initial allegations of Libor manipulation suggested that banks were manipulating Libor submissions to appear less risky (Mollenkamp and Whitehouse (2008)). Following these allegations, the first academic studies focused on testing the signaling hypothesis and compared Libor submissions to other proxies of borrowing costs (Wong (2009), Abrantes-Metz, Kraten, Metz, and Seow (2012), Kuo, Skeie, and Vickery (2012), and Monticini and Thornton (2013)). The evidence regarding manipulation in these papers is at best mixed. For example, Abrantes-Metz et al. (2012) and Kuo et al. (2012) do not find conclusive evidence that Libor diverges from comparable rates during the crisis. Relatedly, Abrantes-Metz and Villas-Boas (2011) and Rauch, Goettsche, and Mouaaouy (2013) show that Benford's law on the distribution of leading digits in random numbers is violated for Libor rates. In a similar vein, Fouquau and Spieser (2014) document breaks in the individual bank Libor submissions. 
Motivated by the fact that banks have large holdings of contracts tied to Libor, Snider and Youle (2012) explore the possibility of Libor manipulation driven by banks' incentive to profit from their Libor sensitive assets. We refer to this possibility as the cash flow hypothesis. In their model of the submission process, panel banks balance the cash flow gains from manipulation against the cost of being discovered. Their model predicts a bunching effect around particular submission levels, which they confirm empirically. More recently, Youle (2014) builds a similar model based on a non-cooperative game. Guided by the model, he estimates constant bank-level exposures to Libor and shows that Libor was downward biased during the recent crisis.

In comparison to these studies, we use a broader cross-section of Libor submissions and simultaneously explore the cash flow and signaling hypotheses for Libor manipulation. We show that manipulation operated mainly through the cash flow hypothesis. In contrast to Youle (2014), we estimate time-varying bank-level exposures to Libor. Collusion among the banks in our setting arises endogenously from similarities in banks' Libor exposures. Importantly, we also analyze how the extent of Libor manipulation varies with enforcement intensity of the regulators over time and in cross-section.

The literature on Libor manipulation also proposes changes in market design to prevent future Libor manipulation (Wheatley (2012), Abrantes-Metz and Evans (2012), Duffie, Skeie, and Vickery (2013), Chen (2013), Duffie and Stein (2015), Hou and Skeie (2014), Duffie and Dworczak (2014), Eisl, Jankowitsch, and Subrahmanyam (2015), and Coulter and Shapiro (2014)). This literature calls for greater reliance on transaction-based measures of borrowing costs and improvements in the method used to calculate Libor. Some of these suggestions were implemented in 2013. In comparison, our results imply that increased enforcement intensity can be effective in preventing future Libor manipulation even with no changes in market design.

Finally, our paper makes a methodological contribution. While many previous papers use multi-factor models to estimate banks' interest rate exposure from equity returns (Flannery and James (1984) and Acharya and Steffen (2015)), we cross-validate this approach using banks' balance sheet data and data on syndicated loans. ${ }^{11}$

\footnotetext{
${ }^{11}$ Begenau, Piazzesi, and Schneider (2013) develop a high frequency measure of a bank's interest rate exposure. Our approach is distinct from theirs in that we do not make any assumptions about the underlying interest rate model.
} 


\section{Libor computation and sources of manipulation}

In this section, we review the history of Libor computation and discuss how Libor can be subject to manipulation. Based on the potential benefits and the associated costs from manipulating Libor, we develop our testable hypotheses.

\subsection{Libor computation}

Libor was introduced in 1986 by the British Banking Association (BBA). Over the years, it became a major benchmark rate for short-term interest rates and is now used as a reference rate for a broad range of spot and derivatives financial contracts. Some $\$ 300$ trillion of financial assets are tied to Libor, according to Wheatley (2012).

Two important changes have been made to the way Libor is computed. The first change was in 1999. Before 1999, Libor was based on banks' estimates of other banks' borrowing costs. Starting in 1999, Libor has been based on banks' estimates of their own borrowing costs. The second change came in 2013 in response to the probes into Libor manipulation. These changes include the introduction of measures aimed at reducing the potential for Libor manipulation and the transfer of the Libor administration from the BBA to the ICE Benchmark Administration (IBA) ${ }^{12}$ To isolate the effects of the changes in the way Libor is computed, as well as recent regulatory changes, we focus on the time period from 1999 through 2012.

During this period, Libor was computed by the BBA for 10 distinct currencies and 15 different maturities. We refer to these 150 combinations as currency-maturity pairs. The procedure to compute Libor was as follows. Around 11 am each day, the BBA collected interest rate data for each currency and maturity from panel banks via a survey, which required banks to answer the following question: "At what rate could you borrow funds, were you to do so by asking for and then accepting inter-bank offers in a reasonable market size just prior to 11am?" The number of panel banks varied across time and currencies from 6 for Swedish Krona to 18 for the U.S. Dollar. The panel banks' answers, which we refer to as submissions, were not required to

\footnotetext{
${ }^{12}$ The main changes affect (i) the number of Libor currencies and maturities (as of July 2013, certain Libor currencies and maturities were discontinued), (ii) the dissemination of information of individual bank submission (as of July 2013, individual submissions are no longer publicly available in real time, but with a delay of three months), (iii) the code of conduct (banks must now name a person accountable for Libor submissions and keep records for auditing purposes), and (iv) the administration of Libor (the transfer of the Libor administration from the BBA to the ICE took place on January 31, 2014.)
} 
be based on actual transactions, but were supposed to reflect the panel banks' true borrowing costs. By rule, submissions could not be aimed at maximizing the cash flows that accrue to a panel bank from its Libor-related assets. ${ }^{13}$ Appendix A provides further details.

Libor was then computed as a trimmed average of the submissions. That is, for each currencymaturity pair, submissions were ranked in descending order from highest to lowest. The largest and smallest $25 \%$ of the submissions were trimmed, and the average of the remaining submissions was published at 12:00 noon as the Libor rate for that currency-maturity pair. All individual bank submissions were made publicly available at the same time.

Note that, despite the use of the trimmed average, each panel bank's submission is relevant for the ordering of the submissions and the computation of the Libor. ${ }^{14}$ Thus, trimming does not eliminate panel banks' attempts to manipulate Libor (see also Eisl, Jankowitsch, and Subrahmanyam (2015)).

\subsection{Costs and benefits of Libor manipulation}

Although explicitly prohibited, the self-reported nature of Libor suggests that banks were in a position to report submissions that needed not necessarily to reflect their true borrowing costs. In doing so, banks would weigh the potential gains from misreporting against the associated costs. We use this trade-off to develop our testable hypotheses.

\subsubsection{Incentives for misreporting Libor submissions}

There are two main ways in which panel banks could benefit from manipulating Libor. First, panel banks may attempt to manipulate Libor in order to benefit from higher profits on their Libor-related products. This would benefit shareholders through higher bank valuations, while bank traders and managers would benefit through increased pay and bonuses. Panel banks therefore have an incentive to align their submissions with their individual exposure to Libor (that is, the panel bank's net asset minus liability position in all markets where pricing is linked to Libor). A panel bank with a net long position in Libor-related assets will benefit from an

\footnotetext{
${ }^{13}$ See http://www.bbatrent.com.

${ }^{14}$ Consider the four submissions $2,3,4$, and $5 \%$ and trim the upper and the lower submissions. The average would be computed over submissions $3 \%$ and $4 \%$. Now change the $2 \%$ submission to $6 \%$. The new average would be computed over submissions $4 \%$ and $5 \%$, as the center set changes even though the changed submission is still being trimmed.
} 
increase in Libor, while a bank with a net short position will benefit from a decrease in Libor. This forms our first hypothesis:

H1: Cash flow hypothesis: Panel banks align their Libor submissions with their individual Libor exposures in an attempt to manipulate Libor and profit from their Libor-related positions.

We expect this type of manipulation to occur most often in currency-maturity pairs with high notional volume of interest rate derivatives, because these are the contracts most likely being held by banks and lead to the highest manipulation gains. ${ }^{15}$

The second way a bank can profit from misreporting Libor submissions is by signaling its credit riskiness. In particular, panel banks' submissions are supposed to reflect their true borrowing cost. Market participants could therefore use the submissions to infer panel banks' credit riskiness. This was possible prior to 2013 because all Libor submissions were publicly available in real time. ${ }^{16}$ A high submission by a panel bank (relative to other banks) would indicate that a bank has a higher credit risk, which in turn may lower the panel bank's valuation and increase the demand for collateral from its counterparties. To appear less risky, banks may therefore have an incentive to report submissions that underestimate their true borrowing costs. This forms our second hypothesis:

H2: Signaling hypothesis: Panel banks report low Libor submissions to appear financially sound compared to their peers.

This type of manipulation, however, can persist only if market participants are unaware of misreporting or if it is difficult to estimate banks' credit riskiness from other sources. In a repeated game, market participants can learn about the misreporting and take it into account when estimating banks' credit riskiness. This in turn diminishes banks' incentives for signaling. We may thus expect underreporting to occur only infrequently when (extra) capital for collateral is especially costly and potential benefits from underreporting are highest. This may be the case for the riskiest panel banks in times of financial distress. Furthermore, not all the 150 Libor

\footnotetext{
${ }^{15}$ Note that manipulation in the Libor markets differs from manipulation in other financial markets. While price manipulation in financial markets is typically easiest in illiquid markets with low participation rates, in the case of Libor, the number of panel banks is fixed for each currency. It is therefore natural to expect that the panel banks focus their efforts where their potential gains from manipulation are highest.

${ }^{16}$ To diminish this type of manipulation, under the new regulation, individual submissions become publicly available with a delay of three months.
} 
currency-maturity pairs are equally important for the assessment of a bank's credit riskiness. Indeed, the amount of inter-bank borrowing varies substantially across different Libor rates. We therefore expect that, when investors estimate banks' credit riskiness, they focus on the information contained in the submissions for the most important Libor rate.

\subsubsection{Costs of misreporting Libor submissions}

Misreporting of Libor submissions does not come without costs. There is a legal risk because banks were explicitly asked to align their submissions with their true borrowing costs, and misreporting would be in violation of these rules. The expected legal cost of misreporting is increasing due to the size of the potential penalties and the intensity of prosecutions by regulators (Becker (1968)).

In the case of Libor manipulation, the penalties imposed by regulators are historically high, $\$ 8$ billion cumulatively (see footnote 1 ). Because several banks are still under investigation and civil lawsuits are under way, this number may increase further. This number also ignores any costs related to the loss of reputation, which may be substantial and often outweigh the costs of penalties (Armour, Mayer, and Polo (2010)). Finally, there are costs to individuals responsible for misconduct. ${ }^{17}$ Following Libor prosecutions, several employees involved in fraudulent transactions were dismissed, and many leading bankers resigned. ${ }^{18}$

Taken together, the costs associated with misreporting Libor submissions turned out to be large. We therefore expect them to weigh importantly against the benefits of manipulation and diminish the incentives for misreporting Libor submissions. These costs, however, only became known ex-post. Also, the intensity of monitoring Libor submissions prior to 2008 was low, if not absent. Even after the first allegations of the Libor manipulation in 2008, the BBA argued that Libor continued to be reliable, and many authorities initially contradicted the claims of manipulation. It was only in 2010-2011 that the investigations into Libor manipulation intensified, and the threat of prosecution became severe. In March 2011, a Wall Street Journal article was the first to report that regulators had been investigating several banks in their probe

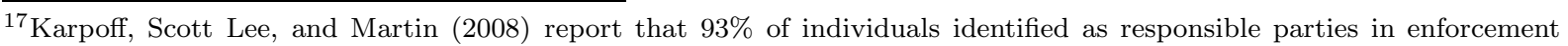
actions lose their jobs by the end of the regulatory enforcement period.

${ }^{18}$ Following the Barclay's settlement, both Marcus Agius, the chairman, and Bob Diamond, the chief executive officer, resigned. Recently, two co-chief executives of Deutsche Bank, Juergen Fitschen and Anshu Jain, resigned after a series of scandals including the Libor rigging affair.
} 
of Libor manipulation (Enrich, Mollenkamp, and Eaglesham (2011)). The first bank to admit to the allegations and reach a settlement agreement with the regulators was Barclays in June 2012.

Based on the timeline discussed above, we believe that the expected costs of Libor manipulation were initially low, but increased rapidly with the intensity of investigations. It is safe to assume that by 2011 all banks were aware of the investigations and the increased probability of being prosecuted for attempts to manipulate Libor. If a credible threat of prosecution with potentially high financial and reputation costs is effective in preventing financial misconduct, we thus expect the evidence for Libor manipulation to subsequently subside. This forms the basis for our last hypothesis.

H3: Prosecution hypothesis: The extent of Libor manipulation decreases with the increased intensity of investigations and prosecutions in 2010-2011.

The expected legal costs may also depend on the regulatory environment or country of incorporation of panel banks. Historically, enforcement intensity is much higher in the U.S. than in other countries (Coffee (2007)). We may thus expect that panel banks incorporated outside the U.S. are initially more prone to misreporting Libor submissions. The investigations in the Libor manipulation revealed, however, that all banks are potential targets of investigations. Indeed, one of the first banks investigated was the Swiss UBS AG. ${ }^{19}$ Any evidence for Libor manipulation should therefore eventually subside for all panel banks, regardless of their country of incorporation.

\section{Methodology}

In this section, we present the empirical approach for testing our hypotheses. We proceed in three stages. In the first stage, we estimate proxies for banks' incentives to misreport submissions based on the signaling and the cash flow hypothesis. In the second stage, we test our hypotheses by relating proxies for incentives to manipulate Libor to future Libor submissions. Finally, in

\footnotetext{
${ }^{19}$ According to Enrich, Mollenkamp, and Eaglesham (2011), the first banks under investigation were Bank of America Corp., Citigroup Inc., and UBS AG. Note also that panel banks incorporated outside of the U.S. would not be exempt from US regulation. Libor is used in the US derivatives markets. An attempt to manipulate Libor can therefore be seen as an attempt to manipulate US derivative markets, and hence a violation of American law. Also, because Libor is used as a reference rate for loans and mortgages, any bank that misreports submissions with the intent to manipulate Libor could be subject to class actions in the U.S.
} 
the third stage, we calculate the potential gains for banks from Libor manipulation.

\subsection{Banks' incentives to manipulate Libor submissions (Stage 1)}

Measurement of incentives to manipulate Libor ideally requires high frequency data on Libor positions for all the individual banks. As discussed in the introduction, such detailed data are unfortunately not available. Our hypotheses, however, suggest an alternative channel that enables us to estimate incentives to manipulate Libor submissions for the cash flow and the signaling hypothesis simultaneously.

In particular, manipulating individual submissions should increase panel banks' market valuation. Under the cash flow hypothesis, aligning individual submissions with Libor exposure pushes Libor in the desired direction and thus increases cash flows that accrue to panel banks from Libor-related positions. Under the signaling hypothesis, underreporting of borrowing costs decreases panel banks' perceived riskiness. Outside investors reward the lower risk in terms of higher bank valuations. These mechanisms suggest a direct link between a panel bank's equity returns and its incentives to manipulate Libor. Thus, a particular panel bank's incentives to manipulate Libor under either hypothesis can be estimated in a multi-factor model that expresses bank equity returns as a function of changes in Libor, changes in bank's individual submissions, and control variables.

Because measurement of incentives to manipulate Libor submissions is crucial for our analysis we pay special attention to the empirical implementation of the model. We balance between three considerations. The first choice relates to the frequency of the data. Although the data are available daily, Libor rates and submissions are very persistent (e.g. for JPY the rates often do not change from one day to the next). To avoid stale estimates while still preserving a relatively high frequency, we estimate the model on weekly data. Second, because banks' exposures to Libor may vary over time substantially, it is important to estimate time-varying coefficients. We capture such variation using a rolling windows approach. To balance the trade-off between the staleness of estimated coefficients measured over longer windows against the statistical uncertainty of the same coefficients measured over shorter windows, we choose windows of 26-weeks (half-a-year). In Section 8.3, we show that our results are robust to reasonable changes in the window length. The final consideration involves the choice of variables 
to control for banks' risk exposures. Banking stocks are in many ways different from nonfinancial firms and the Fama-French and momentum factors do not add much explanatory power to the market model (see for example Gandhi and Lustig (2015)). ${ }^{20}$ Therefore, in lieu of rolling window regressions, we opt for a parsimonious model and control for most important risk factors only, the market excess return and liquidity risk. In Section 8.1, we show that the main results are robust to including changes in the risk-free rate, or changes in the term spread. Results also remain largely unchanged if we control for market excess returns only.

To summarize, using weekly data, we estimate the following rolling-window regression, separately for each panel bank $i$ and for each currency-maturity pair: ${ }^{21}$

$$
r_{i, t}-r_{f, t}=\alpha+\beta_{i}^{\Delta L i b o r} \Delta \text { Libor }_{t}+\beta_{i}^{\Delta S u b} \Delta S u b_{i, t}+\beta_{i}^{M k t}\left(r_{M k t, t}-r_{f, t}\right)+\beta_{i}^{V I X} \Delta V I X_{t}+\epsilon_{i, t},
$$

where $r_{i}$ is the (dollar-denominated) weekly return on bank $i$ 's equity, $r_{f}$ is the weekly USD overnight indexed swap (OIS) rate, Libor is the official Libor for a particular currency-maturity pair, and $S u b_{i}$ is the difference between bank $i$ 's Libor submission and the average Libor submission for all other panel banks for a particular currency-maturity pair. $\Delta$ Libor and $\Delta S u b$ are the weekly changes of these quantities from $t-1$ to $t$. Weekly market excess returns are denoted by $\left(r_{m k t}-r_{f, t}\right)$. Weekly changes in the Chicago Board Options Exchange Market Volatility Index (VIX) control for liquidity risk (Nagel (2012)). All variables are measured as of week $t$.

According to the cash flow hypothesis, the sensitivity to Libor $\beta^{\Delta L i b o r}$ depends on a panel bank's net exposure to Libor and can be either positive or negative. In comparison, the signaling hypothesis suggests that investors react negatively to higher submissions, implying a negative sign on the estimated sensitivity to Libor submissions $\beta^{\Delta S u b}$.

\subsection{Testing hypotheses (Stage 2)}

In the second stage, we test if either the estimated sensitivity to changes in Libor, or the estimated sensitivity to changes in Libor submissions, or both, predict panel banks' average Libor submissions over the following month. We use non-overlapping average monthly submissions

\footnotetext{
${ }^{20}$ Financial stocks are typically excluded from the construction of Fama and French (1992) factors.

${ }^{21}$ This implies that the sensitivities $(\beta \mathrm{s})$ in Eq. (1) should be further indexed by currency-maturity pair $(c, m)$. We omit these subscripts to simplify notation.
} 
data for our dependent variable to avoid spurious correlations driven by the high persistence of Libor submissions at the higher frequencies. ${ }^{22}$ Also, many Libor-denominated assets, such as interest rate swaps or Asian interest rate options, are sensitive to Libor measured over an extended period of time. We thus estimate the following monthly panel predictive regression:

$$
\overline{\text { Submission }}_{i, t+1}=a+\lambda^{\text {Libor }} \beta_{i, t}^{\Delta \text { Libor }}+\lambda^{\text {Sub }} \beta_{i, t}^{\Delta \text { Sub }}+\text { Controls }_{t}+\text { Fixed effects }+u_{i, t+1},
$$

where $\overline{\text { Submission }_{i, t+1}}$ is the average Libor submission for a panel bank $i$ for a particular currency-maturity pair over the month $t+1$. Variables $\beta_{i, t}^{\Delta L i b o r}$ and $\beta_{i, t}^{\Delta S u b}$ denote bank specific estimates for incentives to manipulate Libor for the same currency-maturity pair based on the cash flow and signaling hypotheses from Stage 1 at the end of month $t$. Because proxies for incentives to manipulate Libor are always estimated using data up to time $t$, the regression in Eq. (2) is not subject to look-ahead bias.

Libor submissions should reflect the cost at which a panel bank can borrow funds. We therefore add several controls for bank-level risk. These include the exposures to the market risk factor $\left(\beta^{M k t}\right)$ and the VIX $\left(\beta^{V I X}\right)$ estimated in Eq. (1), the logarithm of bank market capitalization (Size), the domestic 12-month Treasury rate (Yield), and the realized volatility, which we compute as the within-month standard deviation of daily equity returns for bank $i$ $(\mathrm{Vol})$. All control variables are measured as of month $t$.

Note, the data on CDS spreads are available only from 2004 and only for non-Canadian banks. To preserve the whole panel of banks and the long time series, we opt not to include the CDS spreads in the main analysis. In Section 8.3, however, we show on the reduced sample for which the CDS data are available that our main results are robust to controlling for the CDS spreads. In the same section, we also show that results are robust to inclusion of other control variables, such as absolute (or squared) value of sensitivities to changes in Libor, sensitivities to changes in the T-bill rate, and sensitivities to the term spread.

According to our hypotheses, a positive coefficient on the sensitivity to Libor $\lambda^{\text {Libor }}$ is consistent with empirical evidence for the cash flow hypothesis. A positive coefficient on the sensitivity to Libor submissions $\lambda^{S u b}$ is consistent with empirical support for the signaling hypothesis.

\footnotetext{
${ }^{22}$ In Section 8.3, we show that results appear stronger at the weekly frequency. Because of the concerns related to the high persistence of Libor submissions, however, we prefer to rely on the monthly data in the main analysis.
} 


\subsection{Banks' gains from manipulation (Stage 3)}

We calculate the gains from manipulation in terms of an increase in bank market capitalizations. We present details for this calculation only for the cash flow hypothesis, as our subsequent analysis reveals no evidence for the signaling hypothesis. ${ }^{23}$

Note first that the attempt to manipulate Libor (Stage 2) and actual realized gains from manipulation are two distinct concepts. To see this, consider a scenario where the BBA collects submissions from just two otherwise identical panel banks. Assume also that the two panel banks' Libor exposures are of the exact same magnitude, but opposite signs. Then, valuemaximizing banks that align their submissions with their respective Libor exposures manipulate submissions by the exact same amount, but in opposite directions. Thus, these attempts to manipulate Libor exactly offset each other, leaving Libor unaffected.

To document gains from manipulation, while accounting for the above offsetting mechanism, we first construct an unmanipulated average monthly submission that each panel bank in our sample would have hypothetically submitted if it had no incentive to manipulate Libor due to the cash flow hypothesis, i.e. if $\beta^{\Delta L i b o r}$ had been zero. For each panel bank $i$ and for each currencymaturity pair, the predicted average monthly unmanipulated submission $\overline{\text { Submission }}_{i, t+1}^{\text {Unm }}$ equals:

$$
\begin{aligned}
{\overline{\text { Submission }_{i, t+1}^{\text {Unm }}}} & =\overline{\text { Submission }_{i, t+1}}-\lambda^{\text {Libor }} \beta_{i, t}^{\Delta \text { Libor }} \\
& =a+\lambda^{\text {Sub }} \beta_{i, t}^{\Delta \text { Sub }}+\text { Controls }+ \text { Fixed effects }+u_{i, t+1} .
\end{aligned}
$$

We then apply the procedure specified by the BBA to these hypothetical average monthly submissions to compute the unmanipulated trimmed average Libor $\left(\overline{\text { Libor }}_{t+1}^{U n m}\right)$ for a particular currency-maturity pair. Finally, we compute the actual trimmed average monthly Libor from the actual average monthly submissions over the same period $\left(\overline{L i b o r}_{t+1}\right) \cdot{ }^{24}$

A comparison of the unmanipulated average monthly Libor to the actual average monthly Libor allows us to compute the impact of Libor manipulation on the monthly market capitalization of panel banks. Specifically, the dollar manipulation gain (or loss) for a panel bank $i$ in

\footnotetext{
${ }^{23}$ Gains based on signaling hypothesis could be calculated in a similar way.

${ }^{24}$ As explained in Section 5.2, two out of 20 banks in our sample are privately held, and we cannot estimate their Libor sensitivities. For these two banks, we assume that $\beta^{\Delta L i b o r}$ is zero. That is, when calculating unmanipulated Libor, we compute unmanipulated submissions for the public banks and then add back the actual submissions for the private banks.
} 
month $t+1$ for a given currency-maturity pair equals its end-of-month equity market capitalization $\left(M V_{i, t}\right)$ times $\beta_{i, t}^{\Delta L i b o r}$ times the difference between the (changes in) unmanipulated average monthly Libor and the (changes in) actual average monthly Libor. We accumulate manipulation gains for all panel banks across all currency-maturity pairs.

\section{Data}

In this section, we present the data sources and discuss the summary statistics.

\subsection{Libor and individual bank's Libor submissions}

We collect daily data for Libor and Libor submissions from Bloomberg from January 1, 1999 to November 28, 2012. ${ }^{25}$ Libor rates are available for 10 currencies and 15 maturities. Wheatley (2012) estimates that the total outstanding notional value of Libor-linked derivatives in 2012 was approximately $\$ 300$ trillion, with nearly $77 \%$ of this volume in markets for interest rate swaps. In Table 1, we reproduce the statistics from Wheatley (2012). Four currencies, the United States Dollar (USD), Great British Pound (GBP), Japanese Yen (JPY), and the Swiss Franc (CHF), together account for the entire volume of interest rate swaps in June 2012. Furthermore, nearly all these swap contracts reference the 1-, 3-, or 6-month Libor. Therefore, we restrict our analysis to these 12 currency-maturity pairs. ${ }^{26}$

[Table 1 about here]

For each of these 12 currency-maturity pairs, we collect individual submissions for all panel banks. The panel banks include all banks surveyed by the BBA for determining the daily Libor. The number of panel banks varies with currency from 11 for the CHF to 18 for the USD. The full list of panel banks for each currency is in Appendix B.

For the most important maturities within each Libor currency as identified in Table 1, namely the USD 3-month, GBP 6-month, JPY 6-month, and CHF 6-month, we plot in Figure 1

\footnotetext{
${ }^{25}$ November 28, 2012 corresponds to the date when we downloaded the data.

${ }^{26}$ A report published by the Bank of International Settlement in June 2012 (BIS (2012a)) indicates that nearly $92 \%$ of the notional value of all over-the-counter interest rate derivatives are denominated in USD, GBP, or the JPY. Note also that floating payments for derivatives denominated in Euro are often tied to Euribor and not the Euro Libor (See BIS (2012b), p. 21-22). For this reason, we exclude Euro Libor from our analysis.
} 
the average banks' submissions and the two standard deviation cross-sectional bands. Detailed summary statistics for all 12 currency-maturity pairs are presented in Table C.1 in Appendix C.

[Figure 1 about here]

Figure 1 reveals that the level of Libor varies substantially across different currencies. Also, the cross-sectional standard deviation of the submissions is low until 2009 and increases steadily thereafter. Therefore, in our Stage 2 regressions, we standardize all dependent and independent variables cross-sectionally within each month and currency-maturity pair. In untabulated results, we also find that both the daily panel banks' submissions and the Libor rates are highly persistent, indistinguishable from a unit root. This motivates the use of changes in Libor and bank submissions at weekly frequencies in estimating incentives for misreporting Libor submissions.

\subsection{Returns and risk measures}

We obtain daily equity returns for the panel banks from Datastream. These are the returns for the entire bank holding company. Thus, our Stage 1 proxy for a panel bank's incentive to misreport submissions captures the total bank Libor exposure, regardless of the subsidiary (commercial bank, investment bank, insurance company, etc.) in which this exposure is held. From Datastream, we also obtain the daily returns for the aggregate stock market indices where the panel banks are headquartered, the panel banks' equity market capitalizations, the risk-free rate for each currency-maturity pair, the T-bill rate, and the rate for overnight unsecured lending between banks (overnight indexed swap (OIS) rate).

To compute excess returns, we subtract from equity returns the OIS rate instead of the Treasury bill rate because the latter is contaminated by a significant flight-to-liquidity component during the crisis. ${ }^{27}$ However, our results are robust to using the T-bill rate rather than the OIS rate. We express all returns in U.S. dollar. In Section 8.3, we verify that keeping equity returns in their respective local currencies does not impact our results.

Our main measure of bank-level risk is the realized volatility of daily bank equity returns.

\footnotetext{
${ }^{27}$ The OIS rate is available only from November 26, 2003 onward. To contruct an OIS rate prior to that date, we first regress the OIS rate on the Treasury bill rate during 2004. We then use the resultant estimates to construct an artificial OIS rate series as the predicted value during January 1999 to November 2003.
} 
For a subsample of banks, for which credit default swaps (CDS) data exist, we show in Section 8.3, that our results are robust to using the 1-year CDS as an alternative risk measure. CDS data come from Datastream and Markit and are only available from 2004 onward and for panel banks which are not incorporated in Canada. Table C.2 in the Appendix C provides summary statistics for our control variables.

Finally, note that two out of a total of 20 banks in our sample are privately held, Rabobank and Norinchukin. Because our empirical approach requires data on publicly traded equity, we exclude these two banks from our main analysis. For the purpose of calculating unmanipulated Libor in estimation of gains, we use the actual submissions for these two banks (see footnote $22)$.

\subsection{Call reports and syndicated loan data}

To validate our measure of Libor exposure, we also collect bank balance sheet data and data on syndicated loans. The income statement and balance sheet data come from the quarterly Call Reports required to be filed by all FDIC-insured banks in the U.S. These data are only available for a subset of banks in our sample that are either incorporated or have significant operations in the U.S. (Bank of America, Citigroup, Deutsche Bank, HSBC, and J. P. Morgan Chase). The data on syndicated loans come from the Thomson Reuters SDC database. We restrict ourselves to those syndicated loans where any of our panel banks were part of the syndicate. These data are collected for the full period 1999-2012.

\section{Results}

We start by presenting the summary statistics for our proxies for incentives to manipulate Libor submissions from Stage 1. Then we report results for the hypotheses tests from Stage 2, which relate our proxies for incentives to manipulate to subsequent Libor submissions. Finally, we present results for Stage 3, where we quantify the gains from Libor manipulation. 


\subsection{Incentives to manipulate Libor submissions (Stage 1)}

Table 2 presents the summary statistics for sensitivities to changes in Libor $\beta^{\Delta L i b o r}$ (Panel A) and sensitivities to changes in Libor submissions $\beta^{\Delta S u b}$ (Panel B) from rolling window estimates of Eq. (1). The first rolling window ends on June 30, 1999 and the last on November 28, 2012. The statistics are reported separately for each currency-maturity pair. To diminish the effect of outliers, we winsorize the sensitivities at the 1 st and 99 th percentiles. $^{28}$

[Table 2 about here]

The cash flow hypothesis does not predict a particular sign for the average $\beta^{\Delta L i b o r}$ because panel banks' Libor-related holdings can be either positive or negative. ${ }^{29}$ We indeed find substantial time-series and cross-sectional variation in Libor sensitivities; $\beta^{\Delta L i b o r}$ is negative on average for the USD and the JPY and positive for the GBP and the CHF. The untabulated $\mathrm{AR}(1)$ coefficient based on all currencies and maturities is 0.63 at the monthly frequency, and decreases to 0.22 and -0.14 at the quarterly and semi-annual frequency. ${ }^{30}$ Thus, Libor exposures exhibit some persistence, but vary over time considerably. This is also apparent in Figure 2, Panel A, where we plot the fraction of Libor betas that change sign within a given number of months. We find that $55 \%$ of betas change sign within three months and $95 \%$ of betas change sign within a year. Note that these statistics are consistent with our balance sheet estimates introduced in Section 7.2. For a subset of banks for which the balance sheet data are available, we find an average $\operatorname{AR}(1)$ for balance sheet Libor exposures at the quarterly frequency of 0.30 . From Figure 2, Panel B, we also see very similar distribution of sign changes with $50 \%$ and $90 \%$ of balance sheet Libor exposures changing sign within three and twelve months. Thus, the distribution of our regression estimates is closely aligned with the balance sheet data. Finally, note that correlations of $\beta^{\Delta L i b o r}$ across different maturities within the same currency are relatively low, ranging between 0.26 and 0.80 . This suggests that Libor sensitivities vary not only over time and across currencies, but also across different maturities.

[Figure 2 about here]

\footnotetext{
${ }^{28}$ In untabulated results, we find that our results are robust when we instead trim the sensitivities.

${ }^{29}$ Each panel bank has large derivative holdings and Libor exposure on these positions can go in either direction.

${ }^{30}$ Note that the first two coefficients are based on partially overlapping stage 1 regressions while the semi-annual AR(1) coefficient is based on non-overlapping data.
} 
According to the signaling hypothesis, investors react negatively to high Libor submissions, which would predict an overall negative sign for the average $\beta^{\Delta S u b}$. Surprisingly, $\beta^{\Delta \text { Sub }}$ is positive on average for most of the currency-maturity pairs. We interpret this as a first indication that underreporting Libor submissions may not always be a viable strategy. Our hypothesis also implies, that the effect may still be found for the riskiest banks in times of financial distress and for the Libor with the most inter-bank lending. Indeed the $\beta^{\Delta S u b}$ is negative for the most relevant rates, such as the 1-month USD, 3-month USD, and 1-month JPY. For example, the average $\beta^{\Delta S u b}$ for the 3-month USD is -0.091. In untabulated results we also find that the average drops to -0.133 for the USD-3M for the riskiest panel banks during the crisis period.

\subsection{Hypotheses testing (Stage 2)}

Our main results are reported in Tables 3 and 4. Each column in the tables refers to a variation of the regression in Eq. (2). We control for bank and time fixed-effects within each currencymaturity pair. The standard errors are robust to heteroscedasticity and clustered by month. We discuss results for each hypothesis in turn.

Cash flow hypothesis. We explore the cash flow hypothesis by testing whether the sensitivity to changes in Libor is positively related to future submissions. In column (1) of Table 3, we first test for this relationship in a univariate regression using data for all the panel banks over

the entire sample. In line with the hypothesis, the estimated coefficient on $\beta^{\Delta L i b o r}$ is positive and significant. Given that the cross-sectional standard deviation of submissions is 2.28 basis points, the estimated coefficient of 0.029 implies that a one standard deviation increase in the Libor exposure of a panel bank results in a subsequent submission that is higher by 0.066 basis points over the following month. Because contracts with a notional value of several hundred trillion dollars are tied to Libor, even a fraction of a basis point can result in large cash flow transfers among investors. Thus, this effect is economically important.

When we include control variables, the magnitude of the effect decreases only marginally, from 0.029 in column (1) to 0.025 in column (3) and the estimated coefficient remains significant. We comment on the evidence regarding the sensitivity to changes in Libor submissions below. The estimated coefficients on the rest of the control variables in column (3) have the expected signs. In line with the borrowing costs being higher for riskier banks, a panel bank's submission 
increases with the bank's exposure to market risk, the bank's exposure to VIX, and realized volatility. ${ }^{31}$ The submission of a panel bank also increases (mechanically) with interest rates. Finally, the submission decreases as the size of the bank increases, consistent with the notion that larger banks are deemed safer by market participants. ${ }^{32}$

Next, we explore whether the effect is more pronounced for currency-maturity pairs with the highest notional value of interest rate derivatives outstanding. To test this, we estimate a variation of Eq. (2), where we interact $\beta^{\Delta L i b o r}$ with two dummy variables, High and Low. Table 1 shows that USD Libor with three-month maturity is by far the most important reference rate for interest rate derivatives, with more than half of all the interest rate swap contracts and floating rate notes tied to this rate. Accordingly, we define the variable High as a binary variable that takes the value one for the USD Libor with three month maturity, and zero otherwise. The variable Low takes the value one for all the remaining currency-maturity pairs, and zero otherwise.

Results are reported in column (4). The estimated coefficient on the $\beta^{\Delta \text { Libor }} \times H i g h$ is 0.046 , which is twice the size of the estimated coefficient on the $\beta^{\Delta \text { Libor }} \times$ Low at 0.023 . This difference in magnitudes suggests that the manipulation due to cash flow is indeed concentrated in the rate most relevant for interest rate derivatives. The somewhat lower significance of $\beta^{\Delta L i b o r} \times H i g h$ (significant at the $10 \%$ level) may be due to the smaller number of observations used in the calculation of the standard errors. Other currency-maturity pairs are also important for the cash flow manipulation because the estimated coefficient on $\beta^{\Delta L i b o r} \times$ Low is significant and only slightly lower than the same coefficient estimated on the full sample in column (1).

All in all, the results provide strong empirical support for the cash flow hypothesis. Next, we discuss our results for the signaling hypothesis.

Signaling hypothesis. We explore the signaling hypothesis by testing whether the sensitivity to changes in Libor submissions is positively related to future submissions. Because the average for the sensitivity to changes in Libor submissions is positive for most of the currencymaturity pairs, we do not expect to find support for this hypothesis in the full sample. Indeed, in a univariate regression in column (2) of Table 3, where we use the data for all panel banks over

\footnotetext{
${ }^{31}$ The Stage 1 coefficients on the sensitivity to market risk and VIX are on average positive.

${ }^{32}$ We cannot rule out that some unobservable risk factor drives both $\beta^{\Delta \text { Libor }}$ and a panel bank's submission. To the extent that such an unobservable risk factor is bank specific, however, it would be captured by the bank and time fixed effects.
} 
our entire sample, the estimated coefficient on $\beta^{\Delta S u b}$ is close to zero and insignificant. Also, the estimated coefficient hardly changes with the addition of control variables as reported in column $(3)$.

The evidence for manipulation due to signaling could still be present for the currencymaturity pair with the most inter-bank lending and during times of financial distress for the riskiest banks. For those sub-samples, the average sensitivity to changes in Libor submissions has the expected negative sign, making underreporting potentially profitable. To explore the evidence for the signaling hypothesis in these sub-samples, we estimate three variations of the regression in Eq. (2), where we add additional interaction terms between $\beta^{\Delta S u b}$ and the dummy variables High/Low, Weak, and Crisis. The variable Weak takes the value one for the banks in the top credit default spread (CDS) tercile in a given month, and zero otherwise. Following Anand, Irvine, Puckett, and Venkataraman (2013), Crisis takes the value one for the period July 2007 through March 2009, and zero otherwise.

Results are reported in columns (5), (6), and (7) in Table 3. Although underreporting may be a viable strategy in these cases, the estimated coefficients on the relevant interaction terms are all insignificant. ${ }^{33}$ We thus conclude that there is no evidence for Libor manipulation due to signaling.

All in all, we find strong evidence for the cash flow hypothesis and no evidence for the signaling hypothesis, suggesting that Libor manipulation was mainly driven by the increased profits from Libor-related products. Next we explore, how the evidence for Libor manipulation varies with the intensity of Libor investigations as stipulated by the prosecution hypothesis.

[Table 3 about here]

Prosecution hypothesis. Given our evidence above, we focus our attention on the cash flow hypothesis. In particular, we start by testing whether the support for cash flow hypothesis subsided as the intensity of Libor investigations increased. We examine this in a variation of the regression in Eq. (2), where we interact $\beta^{\Delta \text { Libor }}$ with two dummy variables, Pre and Post. As discussed in Section 3, a Wall Street Journal article published in 2011 was the first to mention that several banks were being investigated for Libor manipulation allegations. Accordingly, the

\footnotetext{
${ }^{33}$ The number of observations in column (7) is reduced because CDS data are unavailable before 2004 and for Canadian banks.
} 
variable Pre takes the value one for the period before 2011, and zero otherwise. The variable Post takes the value one for the period thereafter, and zero otherwise.

Results reported in column (1) of Table 4 show that the evidence for cash flow manipulation is indeed present only before 2011. The estimated coefficient on the interaction term $\beta^{\Delta L i b o r} \times$ Pre is 0.031 and significant, whereas the estimated coefficient on $\beta^{\Delta L i b o r} \times$ Post is close to zero and insignificant. This disappearance of the evidence for Libor manipulation after 2010 suggests that the threat of prosecutions with important financial costs weighs strongly against the benefits of manipulation and therefore eliminates fraudulent behavior. In Section 8.3, we show that the results are robust to reasonable changes in the timing of our dummy variables Pre and Post.

Next, we test whether the evidence for Libor manipulation is initially stronger for banks incorporated outside of the U.S., where the enforcement was historically weaker. To analyze this, we define two additional dummy variables US and Non-US. ${ }^{34}$ Because the difference should be present only before the investigations intensified and not thereafter, we interact our new dummies with $\beta^{\Delta \text { Libor }} \times$ Pre and $\beta^{\Delta \text { Libor }} \times$ Post.

In line with our hypothesis, results reported in columns (2) and (3) show that the evidence for manipulation is initially present only for banks incorporated outside of the U.S. The estimated coefficient on the interaction term $\beta^{\Delta \text { Libor }} \times \operatorname{Pre} \times$ Non $-U S$ is 0.040 and highly significant, whereas the estimated coefficient on the $\beta^{\Delta L i b o r} \times \operatorname{Pre} \times U S$ is zero. In comparison, we find no evidence for manipulation after 2010 for either U.S. or non-U.S. banks as both coefficients are close to zero and insignificant. These results strengthen the notion that enforcement intensity has an important mitigating effect on misconduct.

The fact that manipulation disappeared for all the panel banks is consistent with a nondiscriminatory policy of regulators, contrary to the allegations raised in the popular press that regulators went after a select group of (foreign) banks. ${ }^{35}$ To address these allegations more directly, we additionally analyze the manipulation evidence for a subset of sanctioned banks. If regulators were selectively prosecuting banks, we would expect to observe no difference in the extent of Libor manipulation between sanctioned and non-sanctioned banks. Also, if their

\footnotetext{
${ }^{34}$ The variable US takes the value one for panel banks incorporated in the U.S., and zero otherwise. The variable Non-US takes the value one for panel banks incorporated outside of the U.S., and zero otherwise.

${ }^{35}$ For example, questions were raised if U.S. regulators used the Libor scandal to target only foreign (European) banks, hinting that other banks were equally guilty but were spared (Economist (2013)).
} 
criteria were predictable, enforcement would not affect the expected costs of manipulation for the exempt banks, and the evidence for Libor manipulation should subsequently diminish only for the prosecuted banks. ${ }^{36}$

To examine this, we define two additional dummy variables Sanc and Non-Sanc. Sanc takes the value one for the panel banks that have been among the first to be investigated and also have received the largest fines, namely the Deutsche Bank, Union Bank of Switzerland, Royal Bank of Scotland, Societe Generale, and Barclays Bank, and zero otherwise. ${ }^{37}$ Non-Sanc takes the value one for all the other banks, and zero otherwise. As before, we interact our new dummies with $\beta^{\Delta \text { Libor }} \times$ Pre and $\beta^{\Delta \text { Libor }} \times$ Post.

Results are reported in columns (4) and (5). In the pre-2011 period, the evidence for manipulation is stronger for the sanctioned banks. The estimated coefficient on $\beta^{\Delta L i b o r} \times$ Pre $\times$ Sanc is high at 0.054 and significant, whereas the estimated coefficient on $\beta^{\Delta L i b o r} \times \operatorname{Pre} \times$ Non-Sanc is much smaller at 0.018 and insignificant. After 2010, we find no statistically significant evidence for manipulation for either sanctioned or unsanctioned banks. These results are inconsistent with the allegations in the popular press and provide further support for the non-discriminatory policy of regulators. ${ }^{38}$

[Table 4 about here]

\subsection{How much did the panel banks gain from manipulation? (Stage 3)}

To measure economic magnitudes of the documented manipulation and to better compare the associated costs and benefits, we next present the estimated gains from Libor manipulation. As detailed in Section 4.3, these are computed as the cumulative sum of monthly changes in the market value from Libor manipulation for the panel banks. Following the above empirical evidence on Libor manipulation, all the gains are calculated for the cash flow hypothesis and for the period from 1999 through December 2010. The results are reported in Table 5. Columns (1) through (3) correspond to the results reported in columns (1), (2) and (4) of Table 4. The

\footnotetext{
${ }^{36}$ In a similar vein, Kedia and Rajgopal (2011) find that firms located closer to the SEC and more likely to be prosecuted by the SEC are less likely to manipulate their financial statements.

${ }^{37}$ The list excludes Rabobank (which also received a large fine of $\$ 1.07$ billion) because it is privately held.

${ }^{38}$ If we extend the definition of the Sanc dummy by including the three remaining banks that received substantially lower fines, namely Lloyds, J.P. Morgan, and Citi, the estimated coefficient on Sanc remains significant and greater than the estimated coefficient on Non-Sanc, although the difference narrows. We obtain similar results if we instead sort by banks incorporated within and outside the European Union.
} 
$t$-statistics in parenthesis below the estimated dollar amounts refer to the statistical significance of the average monthly gain for the panel banks involved in the computation of the cumulative gains in each column.

[Table 5 about here]

In Column (1), we report that the total cumulative gains from manipulation for all panel banks and Libor rates from 1999 through 2010 amount to $\$ 29.319$ billion and are highly significant. This number corresponds to approximately $\$ 1.191$ million per Libor rate per bank per month. Considering that hundreds of trillions of dollars are tied to Libor, the estimated gains appear reasonable. ${ }^{39}$

Consistent with our analysis above, the cumulative gains are higher for the Non-US banks ( $\$ 26.440$ billion) as compared to the US banks (\$8.369 billion). The cumulative gains for the five banks with the largest penalties imposed by the regulators (Sanc=1) are $\$ 13.921$ billion, while for the other 13 banks the gains amount to $\$ 20.161$ billion.

As our measure of gains is expressed in terms of the market value of banks and thus measures gains to bank shareholders, it can be compared to penalties, which are also born by shareholders. For the five banks with the largest fines, the cumulative sum of penalties amounts to $\$ 6.2$ billion dollars or approximately half the cumulative gains described above. Although gains were realized earlier than penalties and are thus more valuable, the penalties weigh strongly against the benefits of manipulation, especially because the penalties do not include reputation costs and costs related to civil lawsuits.

\section{Cross-validation of Libor exposure}

In this section, we provide two tests to cross-validate our proxy for Libor exposure from the main analysis. First, we document that $\beta^{\Delta L i b o r}$ increases when a bank's Libor exposure increases through newly issued syndicated loans. Second, for a subset of panel banks, we show that $\beta^{\Delta L i b o r}$ is correlated with Libor exposures constructed from quarterly balance sheet data.

\footnotetext{
${ }^{39}$ For example, Deutsche Bank made over $\$ 654$ million in profit in 2008 from trading Libor-related derivatives only (Eagle$\operatorname{sham}(2013))$.
} 


\subsection{Syndicated loans data}

One of the sources of a bank's Libor exposure are syndicated loans. When a bank issues a new loan with a floating interest rate referencing Libor, its exposure to Libor should increase. We therefore expect our measure of net exposure to Libor $\left(\beta^{\Delta L i b o r}\right)$ to increase with the amount of syndicated loans issued. The effect should be stronger when the amount of syndicated loans is sizeable in comparison to the market capitalization of the bank.

We test this prediction in a variation of the regression specified in Eq. (1). In particular, we run the following panel regression for each panel bank for each currency-maturity pair:

$r_{i, t}-r_{f, t}=\alpha+\beta_{i}^{\Delta \text { Libor }} \Delta$ Libor $_{t}+\beta_{i}^{\text {Synd }}$ Synd $_{i, t}+\beta_{i, t}^{\Delta \text { Libor } \times \text { Synd }} \Delta$ Libor $_{t} \times$ Synd $_{t}+\gamma_{i}$ Control $_{i, t}+\epsilon_{i, t}$,

where Synd is the log ratio of the total syndicated loans outstanding for panel bank $i$ to its market capitalization at the end of week $t$. The variables Synd and Libor are always measured with respect to the same currency-maturity pair. Control variables include market excess returns $\left(r_{M k t}-r_{f}\right)$ and changes in VIX $(\Delta V I X)$. If Libor exposure is properly measured through $\beta^{\Delta L i b o r}$, we expect the coefficient on the interaction term $\Delta$ Libor $\times$ Synd to be positive.

We obtain the data on syndicated loans from Thomson Reuters SDC. These data provide all syndicated loans from 1999 to 2012 and include information on the loan amount, the currency, the maturity, the date the loan is executed, and the interest rate of the loan. Importantly, the data indicate if the interest rate on the loan is floating or fixed. If the interest rate is floating, both the reference rate and the maturity of the specified reference rate are provided. Altogether, the data list 159,248 distinct syndicated loans for our sample period. We keep only those loans where the interest rate on the syndicated loan is floating, where the rate references Libor denominated in USD, GBP, JPY, or CHF, and where at least one panel bank is part of the syndicate. ${ }^{40}$ This leaves us with 37,104 observations. Note that most syndicated loans are executed jointly by several banks, and the data do not indicate the loan amount for which each bank in the syndicate is responsible. We assume that the loan amount is divided equally among

\footnotetext{
${ }^{40}$ In a few instances SDC provides information regarding the currency but not the maturity of the reference Libor. In these cases, we assume that the reference rate is for the maturity with the highest notional value of interest rate derivatives outstanding (3-month for the USD and 6-month for GBP, JPY, and CHF, respectively). We confirm that dropping observations with the missing maturity information has no qualitative impact on our results.
} 
all the participating banks. ${ }^{41}$

[Table 6 about here]

Table 6 reports the results for the regression in Eq. (4). In line with our prediction, the estimated coefficient on $\Delta$ Libor $\times$ Synd in column (1) is positive and significant. Repeating the analysis for the most important currencies, USD in column (2) and GBP in column (3), we find that the documented relationship is stable, although not always statistically significant. ${ }^{42} \mathrm{We}$ interpret this evidence as supportive of $\beta^{\Delta L i b o r}$ reflecting a panel bank's net exposure to Libor.

\subsection{Balance sheet data}

Next, we cross-validate our proxy for banks' Libor exposure using 'Report of Condition and Income' (Call Report) data, required to be filed by all FDIC-insured banks in the U.S. While the data on banks' interest rate sensitive assets and liabilities are available from several sources, only the Call Reports include detailed information regarding banks' interest rate derivatives portfolios. These data are important for our purpose because banks have large trading portfolios that in many cases exceed the size of their loan portfolios. Unfortunately, Call Reports data exist only for banks with substantial operations in the U.S. This restricts our sample to just five panel banks, namely Bank of America, Citigroup, Deutsche Bank, HSBC, and J. P. Morgan Chase. $^{43}$

From the Call Reports, we collect data on total assets $(T A)$, total liabilities $(T L)$, total debt $(T D)$, notional value of interest derivatives used for hedging (IRDH) and proprietary trading $(I R D T)$, and the net trading income generated by a bank's interest rate derivatives portfolio $(N T I)$.

Note that the data do not reference the interest rates of the individual instruments. Because Call Reports cover only banks' U.S. operations and most of the interest rate derivatives are tied to the USD Libor, we assume that all the data are referencing USD Libor. This is a strong assumption, but an innocuous one as long as the proportion of interest sensitive holdings related

\footnotetext{
${ }^{41} \mathrm{An}$ alternate method would be to assume that the loan amount is divided among banks in direct proportion to their market capitalizations. However, not all banks participating in the market for syndicated loans are publicly traded and for private banks there is no data regarding market capitalization.

${ }^{42}$ For JPY and CHF, we do not have enough observations to reliably estimate Eq. (4).

${ }^{43}$ Of these five banks, information regarding Deutsche Bank and HSBC only covers their U.S. subsidiaries and not the entire bank holding company.
} 
to USD Libor does not vary over time excessively. The data also do not specify the direction of the exposure of interest rate derivatives held for trading (IRDT). To determine the direction of this exposure, we divide the quarterly net trading income generated by a bank's interest rate derivatives portfolio $(N T I)$ by the quarterly change in the $m$-month USD Libor. If this term is positive (negative), we assume that the overall direction of the interest rate trading portfolio in a given quarter is long (short) Libor. We calculate this direction separately for the 1-, 3-, and 6-month maturities.

Using these data, we define a bank's quarterly balance sheet exposure $(B S E)$ to USD Libor in a given quarter for maturity $m$ as:

$$
B S E_{m}=\frac{T A-\left(T L+T D+I R D H+I R D T \times \operatorname{sign}\left[\frac{N T I}{\Delta L_{i b o r}}\right]\right)}{T A} .
$$

Summary statistics for the $B S E$ variable and the underlying data are discussed in Appendix D, Table D.1. In Section 6.1, we already noted that the AR(1) coefficient and the distribution of sign changes for the $B S E$ is very comparable to our Stage 1 proxy for banks' Libor exposure. Now, we explore this relation more formally. In particular, we run the following pooled regression for each USD Libor maturity $m$ for all five banks with available data:

$$
\bar{\beta}_{m, t}^{\Delta L i b o r}=\alpha_{m}+\delta_{m} B S E_{m, t}+\varepsilon_{t}
$$

where $\bar{\beta}_{m, t}^{\Delta L i b o r}$ denotes the average USD Libor exposure from Eq. (1) over quarter $t$ and $B S E_{m, t}$ is the balance sheet exposure derived above at the end of quarter $t .{ }^{44}$

The results are reported in Table 7 . Columns (1) through (3) present results for the 1, 3, and 6-month maturities. In column (4), the left-hand-side and the right-hand-side variables in Eq. (6) are averaged across the maturities. The coefficients are multiplied by 100 and expressed in percentages.

[Table 7 about here]

Our proxy for Libor exposure $\beta^{\Delta L i b o r}$ correlates positively with the exposure estimated from the Call Reports. The estimated coefficient on balance sheet exposure BSE for different maturities

\footnotetext{
${ }^{44}$ The results are robust to using $\beta_{m, t}^{\Delta L i b o r}$ measured over the last week of quarter $t$ rather than the average over the whole quarter $t$.
} 
is always positive and significant at either $5 \%$ or $10 \%$ level. The highest $R^{2}$ of 0.057 is observed for the 3-month maturity, which corresponds to an implied correlation of approximately $24 \%$. For the average specification in column (4), the $R^{2}$ is 0.037 , with an implied correlation of nearly $20 \%$. These results suggest that our proxy for Libor exposure contains information similar to the measure of interest rate exposure estimated from balance sheet data.

\section{Robustness}

In this section, we conduct several robustness checks. We first address the potential concern that our results are driven by the differences in banks' general interest rate risk exposures. Then, we address the potential endogeneity issues in the estimation of the Libor sensitivities. Finally, we report other robustness checks with respect to our modeling choices. All the robustness checks are reported in Table 8 and correspond to our main results for the prosecution hypothesis reported in column (1) of Table 4. Accordingly, we focus our attention on the significance of the estimated coefficient on $\beta^{\Delta L i b o r} \times$ Pre.

[Table 8 about here]

\subsection{Interest rate risk}

A potential concern is that Libor is highly correlated with other short term interest rates and our measure of Libor exposure is a general measure of the interest rate risk, i.e. a duration measure. This could give rise to an alternative explanation for our results according to which the positive association between the banks' exposures to Libor and the subsequent submissions is simply due to banks setting higher submissions in response to the increased interest rate risk. To address this concern, we provide three additional tests.

First, note that the interest rate risk (duration) depends on the magnitude of the interest rate exposure rather than the sign of the interest rate exposure. Thus, according to the interest rate risk explanation, Libor submissions should be positively related to the magnitude of the Libor exposure, and not the signed value of the Libor exposure, which we use in our main analysis. To test this implication, we repeat our main results by adding either the absolute value or the squared value of banks' Libor exposures as additional control variables. Results are reported 
in Panel A, columns (1) and (2). The estimated coefficients on the added variables are close to zero and insignificant. In the meantime, our main coefficient on the signed Libor exposure remains largely unaffected.

Second, to further address the issue of close relation between the Libor and other short-term interest rates, we use changes in the OIS rate (our proxy for the risk-free rate) as an additional control variable in stage 1, see Eq. (1). We then repeat our main results while adding the estimated parameter to changes in T-bill from Eq. (1) as an additional control variable. Results are reported in Panel A, column (3). The estimated coefficient on the sensitivity to changes

in the T-bill is positive and marginally significant. Our main coefficient on Libor exposure decreases somewhat, but remains significant.

Finally, to account for other sources of interest rate risk, we include the term spread in Eq. (1). As above, we then repeat our main results while adding the estimated coefficient to changes in term spread from Eq. (1) as an additional control variable. In Panel A, column (4), we note that the estimated coefficient on the sensitivity to term spread is insignificant and our main coefficient even increases. All in all, these tests suggest that our results are not driven by the differences in banks' interest rate risk exposures.

\subsection{Endogeneity}

Our measure of Libor sensitivity in the main analysis is the estimated coefficient in the regression of bank stock returns on changes in Libor and control variables in Eq. (1). Because our subsequent analysis suggests that Libor is manipulated, our proxy for Libor exposure may be endogenous and hence biased. In particular, if all panel banks manipulate Libor in the direction of their interest rate exposure, then Libor is a function of the average Libor exposure. This in turn may lead to spurious results.

To address this concern, we estimate our Libor exposures using an instrumental variable approach. As an instrument, we use the risk-free rate that corresponds to Libor in currency and maturity. The risk-free rate varies across currency-maturity pairs and is correlated with Libor, but uncorrelated with manipulation. This suggests that the risk-free rate is a valid instrument and should lead to unabiased estimates of Libor exposure.

We implement our instrumental variable approach using the standard two-stage least-squares 
approach. In the first stage, we regress changes in Libor for each currency-maturity pair on the corresponding changes in the risk-free rate while controlling for market excess returns and changes in VIX. Next, we replace the changes in Libor in Eq. (1) with the fitted value from the first stage regression. As in the main analysis, we use a rolling window approach. ${ }^{45}$

Results based on instrumented Libor exposures are reported in Panel A, column (5). While our main coefficient on $\beta^{\Delta L i b o r} \times$ Pre decreases somewhat, it remains statistically significant and economically important. This suggests that our conclusions are robust to endogeneity concerns.

\subsection{Other robustness analysis}

In this subsection, we analyze the sensitivity of our results to other modeling choices. First, in the main analysis, we estimate our proxies for incentives to manipulate Libor in Eq. (1) using 26-week rolling windows. To analyze how sensitive the results are to the length of the window, we now vary the window size from 20- to 45 -weeks in steps of 5-weeks and report results for each window size in Panel B of Table 8. The estimated coefficient on $\beta^{\Delta L i b o r} \times$ Pre displays a hump shape pattern in the length of the window size. It first increases from 0.018 for the 20-week window size to 0.040 for the 35 -week window size and then decreases slightly to 0.039 for the 45-week window size. The estimated coefficient, however, is significant for any window size. This pattern is consistent with the trade-off between the statistical uncertainty of the coefficients measured over shorter windows and staleness of estimated coefficients measured over longer windows. Note also that the estimated coefficient on $\beta^{\Delta L i b o r} \times$ Post is always insignificant, in line with our hypothesis. We thus conclude that our results are robust to a wide range of window sizes.

Second, because of high persistence of Libor submissions, we test our hypotheses in the main analysis by relating proxies for incentives to manipulate Libor to (non-overlapping) average submissions over the following month. Now, we repeat our analysis using weekly frequency. That is, we test for the relationship between the incentives to manipulate Libor and (nonoverlapping) average submissions over the following week. As reported in Panel C, column (1), of Table 8, our main results appear statistically stronger than in the main analysis.

\footnotetext{
${ }^{45}$ To validate our instrumental variable approach, we apply the standard F-test for overidentifying restrictions. The test is strongly rejected across all currencies and maturities, that is, changes in yields appear as strong instruments for changes in the corresponding Libor.
} 
Third, in the main analysis, we estimate our proxies for incentives to manipulate Libor in Eq. (1) while controlling for excess market return and changes in VIX. Now, we repeat our analysis controlling only for excess market return. As reported in Panel C, column (2), our main coefficient decreases somewhat, but it remains statistically significant.

Fourth, in the main analysis, the pre-period (variable Pre) ends in December 2010. Now, we vary the length of the pre-period by three months and present results for the pre-period ending in September 2010 and March 2011. As reported in Panel C, columns (3) and (4), the estimated coefficients are almost identical to our main specification.

Fifth, in the main analysis, we use returns denominated in USD. In Panel C, column (5), we present results when the panel bank equity and market returns are denominated in the currency of the countries of incorporation of the panel banks. The main results remain largely unchanged.

Finally, in the main analysis, we control for bank riskiness using realized volatility of bank equity returns. Now we use credit default swaps (CDS) as an additional measure of bank riskiness and repeat the analysis on a subsample, for which CDS data exist. As reported in Panel C, column 6, the estimated coefficient on the CDS is highly significant. Our main results, however, remain largely unchanged, despite the additional control variable and the reduced sample size. ${ }^{46}$

\section{Conclusion}

The recent banking scandals called into question the integrity of financial markets and opened up a discussion about the role of regulation and enforcement. In this paper, we contribute to this discussion by analyzing the events surrounding the manipulation of London Interbank Offer Rate (Libor).

We study the extent of Libor manipulation through the lens of cost-benefit analysis of financial misconduct. We start by exploring and testing for different motives for Libor manipulation. Using a large cross-section of banks' Libor submissions 1999-2012, from which Libor is subsequently computed, we document that Libor manipulation was widespread, and the dominant motive was the profit arising from banks' positions tied to the value of Libor.

\footnotetext{
${ }^{46}$ We also considered using changes in the difference between the banks' CDS and the average CDS for all panel banks as an additional control variable in Eq. (1). We then added the resulting sensitivity to CDS changes as a control variable in Eq. (2). Again, our main results remain unchanged.
} 
Next, we analyze how the evidence for manipulation varies with enforcement intensity. Consistent with enforcement being historically weaker outside the U.S., we find that Libor manipulation was initially present only for non-U.S. banks. After the Libor scandal broke out and investigations of the alleged manipulation of Libor intensified in 2010-2011, the evidence for manipulation disappeared. Moreover, manipulation disappeared for all the banks, regardless of their country of incorporation and whether or not they had already been sanctioned. Our results thus suggest that a credible threat of prosecution with large punitive damages has a strong disciplinary effect and can be effective in preventing financial market misconduct. 


\section{References}

Abrantes-Metz, Rosa M., and David S. Evans, 2012, Replacing the Libor with a Transparent and Reliable Index of Interbank Borrowing: Comments on the Wheatley Review of Libor Initial Discussion Paper, Working Paper, The Law School, The University of Chicago.

Abrantes-Metz, Rosa M., Michael Kraten, Albert D. Metz, and Gim S. Seow, 2012, Libor Manipulation?, Journal of Banking $\mathscr{E}$ Finance 36, 136-150.

Abrantes-Metz, Rosa M., and Sofia B. Villas-Boas, 2011, Tracking the Libor Rate, Applied Economics Letters 18, 893-899.

Acharya, Viral, and Sascha Steffen, 2015, The Greatest Carry Trade Ever? Understanding Eurozone Bank Risks, Journal of Financial Economics 115, 215-236.

Agarwal, Vikas, Naveen D. Daniel, and Narayan Y. Naik, 2011, Do Hedge Funds Manage Their Reported Returns?, Review of Financial Studies 24, 3281-3320.

Anand, Amber, Paul Irvine, Andy Puckett, and Kumar Venkataraman, 2013, Institutional Trading and Stock Resiliency: Evidence from the 2007-2009 Financial Crisis, Journal of Financial Economics 108, 773-797.

Armour, John, Colin Mayer, and Andrea Polo, 2010, Regulatory Sanctions and Reputational Damage in Financial Markets, CEPR Discussion Papers 8058 C.E.P.R. Discussion Papers.

Becker, Gary S., 1968, Crime and Punishment: An Economic Approach, Journal of Political Economy 76, 169-217.

Begenau, Juliane, Monika Piazzesi, and Martin Schneider, 2013, Banks Risk Exposures, Working Paper, Stanford University.

Ben-David, Itzhak, Francesco Franzoni, Augustin Landier, and Rabih Moussawi, 2013, Do Hedge Funds Manipulate Stock Prices?, Journal of Finance 68, 2383-2434.

Bergstresser, Daniel, and Thomas Philippon, 2006, CEO Incentives and Earnings Management, Journal of Financial Economics 80, 511-529.

Bhattacharya, Utpal, and Hazem Daouk, 2002, The World Price of Insider Trading, Journal of Finance 57, 75-108.

Biggerstaff, Lee, David C. Cicero, and Andy Puckett, 2014, Suspect CEOs, Unethical Culture, and Corporate Misbehavior, Journal of Financial Economics 117, 98-121.

BIS, 2012a, International Banking and Financial Market Developments, Quarterly Review December 2012, Basel.

— , 2012b, OTC Derivatives Statistics at End-June 2012, Statistical Release November 2012.

Bollen, Nicolas P.B., and Veronika K. Pool, 2009, Do Hedge Fund Managers Misreport Returns? Evidence from the Pooled Distribution, Journal of Finance 64, 2257-2288.

Burns, Natasha, and Simi Kedia, 2006, The Impact of Performance-Based Compensation on Misreporting, Journal of Financial Economics 79, 35-67. 
Chen, Jiakai, 2013, Libor's Poker: Interbank Borrowing Costs and Strategic Reporting, Working Paper, University of California Berkeley.

Coffee, John C., 2007, Law and the Market: The Impact of Enforcement, University of Pennsylvania Law Review 229, 156.

Corwin, A. Shane, Stephannie Larocque, and Mike Stegemoller, 2015, Investment Banking Relationships and Analyst Affiliation Bias: The Impact of Global Settlement on Sanctioned and Non-Sanctioned Banks, Working Paper, University of Notre Dame.

Coulter, Brian, and Joel Shapiro, 2014, A Mechanism for Libor, Working Paper, University of Oxford.

Duffie, Darrell, and Piotr Dworczak, 2014, Robust Benchmark Design, Working Paper, Stanford University.

Duffie, Darrell, David Skeie, and James Vickery, 2013, A Sampling-Window Approach to Transactions-Based Libor Fixing, Working Paper, Federal Reserve Bank of New York.

Duffie, Darrell, and Jeremy C. Stein, 2015, Reforming Libor and Other Financial-Market Benchmarks, Journal of Economic Perspectives 29, 191-212.

Dyck, Alexander, Adair Morse, and Luigi Zingales, 2014, How Pervasive Is Corporate Fraud?, Working Paper, University of Chicago.

Eaglesham, Jean, 2013, Bank Made Huge Bet, and Profit, on Libor, Wall Street Journal January 10.

Economist, 2013, The Long Arm of American Justice, The Economist July 20.

Eisl, Alexander, Rainer Jankowitsch, and Marti G. Subrahmanyam, 2015, The Manipulation Potential of Libor and Euribor, Working Paper, New York University.

Enrich, David, Carrick Mollenkamp, and Jean Eaglesham, 2011, U.S. Libor Probe Includes BofA, Citi, UBS, Wall Street Journal March 18.

Flannery, Mark J., and Christopher M. James, 1984, The Effect of Interest Rate Changes on the Common Stock Returns of Financial Institutions, Journal of Finance 39, 1141-1153.

Fouquau, Julien, and Philippe K. Spieser, 2014, Statistical Evidence About Libor Manipulation: A "Sherlock Holmes" Investigation, Journal of Banking and Finance, forthcoming.

Gandhi, Priyank, and Hanno Lustig, 2015, Size Anomalies in U.S. Bank Stock Returns, Journal of Finance 70, 733-768.

Hou, David, and David Skeie, 2014, Libor: Origins, Economics, Crisis, Scandal, and Reform, Working Paper, Federal Reserve Bank of New York.

Karpoff, Jonathan, D. Scott Lee, and Gerald S. Martin, 2008, The Consequences to Managers for Financial Misrepresentation, Journal of Financial Economics 88, 193-215.

Kedia, Simi, and Shiva Rajgopal, 2011, Do the SEC's Enforcement Preferences Affect Corporate Misconduct?, Journal of Accounting and Economics 51, 259-278. 
Kuo, Dennis, David Skeie, and James Vickery, 2012, A Comparison of Libor to Other Measures of Bank Borrowing Costs, Working Paper, Federal Reserve Bank of New York.

Lo, Andrew W., 2015, The Gordon Gekko Effect: The Role of Culture in the Financial Industry, NBER Working Paper.

Madureira, Leonardo, Ohad Kadan, Rong Wang, and Zach Tzachi, 2009, Conflicts of Interest and Stock Recommendations: The Effects of the Global Settlement and Related Regulations, Review of Financial Studies 22, 4189-4217.

Mollenkamp, Carrick, and Mark Whitehouse, 2008, Study Casts Doubt on Key Rate, Wall Street Journal May 29.

Monticini, Andrea, and Daniel L. Thornton, 2013, The Effect of Underreporting on Libor Rates, Journal of Macroeconomics 37, 345 - 348.

Nagel, Stefan, 2012, Evaporating Liquidity, Review of Financial Studies 25, 2005-2039.

Rauch, Bernhard, Max Goettsche, and Florian El Mouaaouy, 2013, Libor Manipulation Empirical Analysis of Financial Market Benchmarks Using Benfords Law, Working Paper, Catholic University of Eichstaett-Ingolstadt.

Snider, Connan, and Thomas Youle, 2012, The Fix is In: Detecting Portfolio Driven Manipulation of the Libor, Working Paper, University of California Los Angeles.

Wheatley, Martin, 2012, The Wheatley Review of Libor: Final Report, Discussion paper HM Treasury London.

Wong, Justin, 2009, LIBOR Left in Limbo; A Call for More Reform, North Carolina Banking Institute 13, 365-384.

Youle, Thomas, 2014, How Much Did Manipulation Distort the Libor?, Working Paper, University of Minnesota. 
Table 1: The use of Libor as a reference rate

This table reports the notional value for interest rate swap contracts and floating rate notes referenced to Libor for different currencies and maturities as a percentage of the size of the total market. The data is from Dealogic and the Depositary Trust and Clearing Corporation. The table is adapted from Wheatley (2012, Table 5.A, p. 36). The last row and column report notional value as a percentage of the size of the total market for each maturity and currency, respectively.

\begin{tabular}{lcccc|c}
\hline \hline & $1 \mathrm{~m}$ & $3 \mathrm{~m}$ & $6 \mathrm{~m}$ & $12 \mathrm{~m}$ & Total \\
\hline USD & $5.6 \%$ & $52.8 \%$ & $0.3 \%$ & $0.1 \%$ & $59 \%$ \\
EUR & - & - & $0.1 \%$ & - & $0 \%$ \\
GBP & $0.4 \%$ & $2.9 \%$ & $8.9 \%$ & - & $12 \%$ \\
JPY & $0.1 \%$ & $3.6 \%$ & $23.5 \%$ & - & $27 \%$ \\
CHF & $0.1 \%$ & $0.4 \%$ & $1.6 \%$ & - & $2 \%$ \\
AUD & - & - & - & - & $0 \%$ \\
CAD & - & - & - & - & $0 \%$ \\
NZD & - & - & - & - & $0 \%$ \\
SEK & - & - & - & - & $0 \%$ \\
DKK & - & - & - & - & $0 \%$ \\
\hline Total & $6 \%$ & $60 \%$ & $34 \%$ & $0 \%$ & $100 \%$ \\
& & & & & \\
\hline \hline
\end{tabular}




\section{Table 2: Summary statistics for incentives to manipulate Libor submissions (Stage}

1)

This table reports summary statistics for incentives to manipulate Libor submissions due to the cash-flow hypothesis in Panel A (sensitivities to changes in Libor: $\beta^{\Delta L i b o r}$ ) and incentives to manipulate Libor submissions due to the signaling hypothesis in Panel B (sensitivities to changes in Libor submissions: $\beta^{\Delta S u b}$ ). The sensitivities are obtained by estimating regression in Eq. (1), where we regress bank excess returns on the changes in Libor, changes in the difference between the individual Libor submissions and the average Libor submissions, and control variables (market excess returns and changes in VIX). Results are presented separately for four Libor currencies (USD, GBP, JPY, and CHF) and three maturities (1-, $3-$, and 6-month). All sensitivities are estimated using rolling windows of 26 weeks. The first rolling window ends on June 30, 1999 and the last on November 28, 2012. The estimates are winsorized at the 1st and 99th percentile.

\begin{tabular}{|c|c|c|c|c|c|c|c|c|c|c|c|c|}
\hline \multicolumn{13}{|c|}{ Panel A: $\beta^{\Delta L i b o r}$} \\
\hline Currency-maturity & $\mathrm{N}$ & mean & sd & $\min$ & $\mathrm{p} 25$ & med & p75 & $\max$ & skew & $\operatorname{corr}(1 \mathrm{~m})$ & $\operatorname{corr}(3 \mathrm{~m})$ & $\operatorname{corr}(6 \mathrm{~m})$ \\
\hline USD-1m & 1875 & -0.062 & 1.022 & -4.593 & -0.123 & -0.007 & 0.110 & 4.266 & -0.478 & 1 & & \\
\hline USD-3m & 1892 & -0.051 & 0.552 & -2.633 & -0.149 & -0.004 & 0.121 & 1.936 & -1.141 & 0.602 & 1 & \\
\hline USD-6m & 1887 & -0.006 & 0.399 & -1.908 & -0.095 & 0.002 & 0.099 & 1.588 & -0.741 & 0.534 & 0.681 & 1 \\
\hline GBP-1m & 1815 & 0.047 & 0.985 & -3.412 & -0.105 & -0.009 & 0.105 & 4.233 & 0.763 & 1 & & \\
\hline GBP-3m & 1813 & 0.002 & 0.524 & -2.035 & -0.129 & -0.003 & 0.111 & 2.059 & 0.042 & 0.524 & 1 & \\
\hline GBP-6m & 1813 & 0.012 & 0.433 & -1.580 & -0.095 & -0.002 & 0.089 & 1.819 & 0.434 & 0.428 & 0.804 & 1 \\
\hline JPY-1m & 1683 & -0.147 & 3.937 & -18.350 & -0.704 & 0.001 & 0.706 & 16.720 & -0.513 & 1 & & \\
\hline JPY-3m & 1663 & -0.218 & 4.581 & -23.660 & -0.640 & 0.033 & 0.966 & 14.970 & -1.620 & 0.353 & 1 & \\
\hline JPY-6m & 1688 & -0.261 & 5.588 & -28.940 & -0.769 & 0.029 & 0.808 & 20.720 & -1.448 & 0.264 & 0.529 & 1 \\
\hline CHF-1m & 1675 & -0.002 & 0.779 & -3.479 & -0.102 & 0.004 & 0.143 & 3.060 & -0.748 & 1 & & \\
\hline CHF-3m & 1518 & 0.071 & 0.872 & -3.510 & -0.099 & 0.031 & 0.202 & 4.087 & 0.506 & 0.537 & 1 & \\
\hline CHF-6m & 1519 & 0.025 & 0.660 & -2.670 & -0.119 & 0.019 & 0.181 & 2.586 & -0.330 & 0.272 & 0.468 & 1 \\
\hline \multicolumn{13}{|c|}{ Panel B: $\beta^{\Delta S u b}$} \\
\hline Currency-maturity & $\mathrm{N}$ & mean & sd & $\min$ & $\mathrm{p} 25$ & med & p75 & $\max$ & skew & $\operatorname{corr}(1 \mathrm{~m})$ & $\operatorname{corr}(3 \mathrm{~m})$ & $\operatorname{corr}(6 \mathrm{~m})$ \\
\hline USD-1m & 1875 & -0.066 & 1.291 & -4.540 & -0.613 & -0.036 & 0.513 & 4.425 & -0.106 & 1 & & \\
\hline USD-3m & 1892 & -0.091 & 1.054 & -3.031 & -0.635 & -0.083 & 0.409 & 3.475 & 0.237 & 0.258 & 1 & \\
\hline USD-6m & 1887 & 0.036 & 0.951 & -2.863 & -0.428 & 0.015 & 0.510 & 2.875 & -0.068 & 0.126 & 0.309 & 1 \\
\hline GBP-1m & 1815 & 0.060 & 0.905 & -3.095 & -0.280 & 0.046 & 0.410 & 3.251 & 0.040 & 1.000 & & \\
\hline GBP-3m & 1813 & 0.044 & 0.788 & -2.316 & -0.352 & 0.027 & 0.404 & 2.928 & 0.428 & 0.521 & 1.000 & \\
\hline GBP-6m & 1813 & 0.024 & 0.714 & -2.057 & -0.342 & 0.023 & 0.393 & 2.431 & 0.163 & 0.3986 & 0.519 & 1 \\
\hline JPY-1m & 1683 & -0.210 & 2.534 & -15.001 & -0.520 & 0.021 & 0.454 & 7.761 & -2.412 & 1.000 & & \\
\hline JPY-3m & 1663 & 0.008 & 2.753 & -11.752 & -0.583 & 0.001 & 0.615 & 12.932 & 0.447 & 0.2695 & 1 & \\
\hline JPY-6m & 1688 & 0.287 & 2.982 & -8.789 & -0.496 & 0.046 & 0.637 & 18.526 & 2.789 & 0.020 & 0.317 & 1 \\
\hline $\mathrm{CHF}-1 \mathrm{~m}$ & 1675 & 0.097 & 0.830 & -2.091 & -0.294 & 0.019 & 0.354 & 3.819 & 1.338 & 1.000 & & \\
\hline CHF-3m & 1518 & 0.021 & 0.764 & -2.285 & -0.335 & 0.025 & 0.352 & 2.768 & 0.422 & 0.447 & 1 & \\
\hline CHF-6m & 1519 & 0.044 & 0.600 & -1.956 & -0.243 & 0.040 & 0.352 & 2.003 & -0.082 & 0.196 & 0.410 & 1 \\
\hline
\end{tabular}




\section{Table 3: Testing the cash flow and signaling hypotheses}

This table reports results for the cash flow and signaling hypotheses. Each column refers to a variation of the regression in Eq. (2), where we regress monthly average bank Libor submissions on lagged sensitivities to Libor $\left(\beta^{\Delta L i b o r}\right)$, lagged sensitivities to Libor submissions $\left(\beta^{\Delta S u b}\right)$, interaction terms, and control variables. The regression is estimated by pooling observations for panel banks across four currencies (USD, GBP, JPY, and CHF) and three maturities (1-, 3-, and 6-month). High is defined as one for the USD Libor with 3-month maturity, and zero otherwise. Low is defined as 1- High. Weak is defined as one for the banks in the top credit default spread (CDS) tercile in a given month, and zero otherwise. Crisis is defined as one for the period July 2007 through March 2009, and zero otherwise. Control variables include the sensitivities of bank excess returns to the domestic market excess returns $\left(\beta^{M k t}\right)$, and the changes in VIX $\left(\beta^{V I X}\right)$, the log market capitalization (Size), the one-year yield of the domestic country (Yield), and the realized stock return volatility (Vol). All variables are cross-sectionally standardized. All regressions include bank and time fixed effects within each currencymaturity pair. In parentheses, below the estimated coefficients, are the $t$-statistics based on robust standard errors clustered by month. Statistical significance at the $1 \%, 5 \%$, and $10 \%$ is denoted by three, two, and one asterisks, respectively. The $R^{2}$ is from the regression of the residuals of the dependent and independent variables on the fixed effects. The sample contains monthly observations from July 1999 through November 2012.

\begin{tabular}{|c|c|c|c|c|c|c|c|}
\hline Control & (1) & (2) & (3) & (4) & (5) & (6) & (7) \\
\hline$\beta^{\Delta L i b o r}$ & $\begin{array}{c}0.029^{* * *} \\
(2.910)\end{array}$ & & $\begin{array}{l}0.025^{* *} \\
(2.517)\end{array}$ & & $\begin{array}{l}0.025^{* *} \\
(2.520)\end{array}$ & $\begin{array}{l}0.025^{* *} \\
(2.515)\end{array}$ & $\begin{array}{l}0.026^{* *} \\
(2.399)\end{array}$ \\
\hline$\beta^{S u b}$ & & $\begin{array}{c}-0.009 \\
(-1.193)\end{array}$ & $\begin{array}{l}-0.012 \\
(-1.593)\end{array}$ & $\begin{array}{l}-0.011 \\
(-1.560)\end{array}$ & & & \\
\hline$\beta^{\Delta L i b o r} \times H i g h$ & & & & $\begin{array}{l}0.046^{*} \\
(1.744)\end{array}$ & & & \\
\hline$\beta^{\Delta L i b o r} \times L o w$ & & & & $\begin{array}{c}0.023^{* *} \\
(2.245)\end{array}$ & & & \\
\hline$\beta^{S u b} \times H i g h$ & & & & & $\begin{array}{l}-0.013 \\
(-0.713)\end{array}$ & & \\
\hline$\beta^{S u b} \times$ Low & & & & & $\begin{array}{l}-0.012 \\
(-1.514)\end{array}$ & & \\
\hline$\beta^{S u b} \times($ High $\times$ Crisis $)$ & & & & & & $\begin{array}{c}0.005 \\
(0.116)\end{array}$ & \\
\hline$\beta^{S u b} \times(1-($ High $\times$ Crisis $))$ & & & & & & $\begin{array}{l}-0.012 \\
(-1.619)\end{array}$ & \\
\hline$\beta^{S u b} \times($ High $\times$ Crisis $\times$ Weak $)$ & & & & & & & $\begin{array}{c}-0.087 \\
(-0.912)\end{array}$ \\
\hline$\beta^{S u b} \times(1-($ High $\times$ Crisis $\times$ Weak $))$ & & & & & & & $\begin{array}{l}-0.012 \\
(-1.557)\end{array}$ \\
\hline$\beta^{M k t}$ & & & $\begin{array}{c}0.055^{* * *} \\
(3.600)\end{array}$ & $\begin{array}{c}0.055^{* * *} \\
(3.597)\end{array}$ & $\begin{array}{c}0.055^{* * *} \\
(3.600)\end{array}$ & $\begin{array}{c}0.055^{* * *} \\
(3.602)\end{array}$ & $\begin{array}{c}0.048^{* * *} \\
(2.729)\end{array}$ \\
\hline$\beta^{V I X}$ & & & $\begin{array}{c}0.012 \\
(0.903)\end{array}$ & $\begin{array}{c}0.012 \\
(0.892)\end{array}$ & $\begin{array}{c}0.012 \\
(0.905)\end{array}$ & $\begin{array}{c}0.012 \\
(0.902)\end{array}$ & $\begin{array}{c}0.019 \\
(1.329)\end{array}$ \\
\hline Size & & & $\begin{array}{c}-0.158^{* * *} \\
(-7.998)\end{array}$ & $\begin{array}{c}-0.158^{* * *} \\
(-7.987)\end{array}$ & $\begin{array}{c}-0.158^{* * *} \\
(-7.997)\end{array}$ & $\begin{array}{c}-0.158^{* * *} \\
(-7.990)\end{array}$ & $\begin{array}{c}-0.164^{* * *} \\
(-7.084)\end{array}$ \\
\hline Yield & & & $\begin{array}{c}0.151^{* * *} \\
(6.539)\end{array}$ & $\begin{array}{c}0.150^{* * *} \\
(6.536)\end{array}$ & $\begin{array}{c}0.151^{* * *} \\
(6.537)\end{array}$ & $\begin{array}{c}0.150^{* * *} \\
(6.528)\end{array}$ & $\begin{array}{c}0.144^{* * *} \\
(5.118)\end{array}$ \\
\hline $\mathrm{Vol}$ & & & $\begin{array}{c}0.033^{* *} \\
(2.441)\end{array}$ & $\begin{array}{c}0.033^{* *} \\
(2.440)\end{array}$ & $\begin{array}{c}0.033^{* *} \\
(2.441)\end{array}$ & $\begin{array}{c}0.033^{* *} \\
(2.444)\end{array}$ & $\begin{array}{c}0.034^{* *} \\
(2.401)\end{array}$ \\
\hline $\begin{array}{l}\text { Obs. } \\
R^{2}\end{array}$ & $\begin{array}{c}20,745 \\
0.001\end{array}$ & $\begin{array}{c}20,745 \\
0.000\end{array}$ & $\begin{array}{c}20,745 \\
0.026\end{array}$ & $\begin{array}{c}20,745 \\
0.026\end{array}$ & $\begin{array}{c}20,746 \\
0.026\end{array}$ & $\begin{array}{c}20,747 \\
0.026\end{array}$ & $\begin{array}{c}17,771 \\
0.025\end{array}$ \\
\hline
\end{tabular}




\section{Table 4: Testing the prosecution hypothesis}

This table reports results for the prosecution hypothesis. Each column refers to a variation of the regression in Eq. (2), where we regress monthly average bank Libor submissions on lagged sensitivities to Libor $\left(\beta^{\Delta L i b o r}\right)$, lagged sensitivities to Libor submissions $\left(\beta^{\Delta S u b}\right)$, interaction terms, and control variables. The regression is estimated by pooling observations for panel banks across four currencies (USD, GBP, JPY, and CHF) and three maturities (1-, 3-, and 6-month). Pre is defined as one for the period before 2011, and zero otherwise. Post is defined as 1-Pre. US is defined as one for panel banks incorporated in the U.S., and zero otherwise. Non-US is defined as 1-US. Sanc is defined as one for the five panel banks that have been among the first to be investigated and also received the largest fines, and zero otherwise. Non-Sanc is defined as 1-Sanc. Control variables include the sensitivities of bank excess returns to the domestic market excess returns $\left(\beta^{M k t}\right)$, and the changes in VIX $\left(\beta^{V I X}\right)$, the log market capitalization (Size), the one-year yield of the domestic country ( Yield), and the realized stock return volatility $(\mathrm{Vol})$. All variables are cross-sectionally standardized. All regressions include bank and time fixed effects within each currency-maturity pair. In parentheses, below the estimated coefficients, are the $t$-statistics based on robust standard errors clustered by month. Statistical significance at the $1 \%, 5 \%$, and $10 \%$ is denoted by three, two, and one asterisks, respectively. The $R^{2}$ is from the regression of the residuals of the dependent and independent variables on the fixed effects. The sample contains monthly observations from July 1999 through November 2012 .

\begin{tabular}{|c|c|c|c|c|c|}
\hline Control & $(1)$ & (2) & (3) & (4) & (5) \\
\hline$\beta^{\Delta L i b o r} \times$ Pre & $\begin{array}{c}0.031^{* * *} \\
(2.840)\end{array}$ & & $\begin{array}{c}0.031^{* * *} \\
(2.842)\end{array}$ & & $\begin{array}{c}0.031^{* * *} \\
(2.842)\end{array}$ \\
\hline$\beta^{\Delta L i b o r} \times$ Post & $\begin{array}{l}-0.006 \\
(-0.235)\end{array}$ & $\begin{array}{l}-0.006 \\
(-0.240)\end{array}$ & & $\begin{array}{l}-0.006 \\
(-0.239)\end{array}$ & \\
\hline$\beta^{\Delta L i b o r} \times$ Pre $\times U S$ & & $\begin{array}{l}-0.000 \\
(-0.021)\end{array}$ & & & \\
\hline$\beta^{\Delta L i b o r} \times$ Pre $\times$ Non $-U S$ & & $\begin{array}{c}0.040^{* * *} \\
(3.311)\end{array}$ & & & \\
\hline$\beta^{\Delta L i b o r} \times$ Post $\times U S$ & & & $\begin{array}{c}0.021 \\
(0.627)\end{array}$ & & \\
\hline$\beta^{\Delta L i b o r} \times$ Post $\times$ Non- $U S$ & & & $\begin{array}{l}-0.012 \\
(-0.405)\end{array}$ & & \\
\hline$\beta^{\Delta L i b o r} \times \operatorname{Pre} \times$ Sanc & & & & $\begin{array}{c}0.054^{* * *} \\
(2.969)\end{array}$ & \\
\hline$\beta^{\Delta L i b o r} \times$ Pre $\times$ Non-Sanc & & & & $\begin{array}{c}0.018 \\
(1.500)\end{array}$ & \\
\hline$\beta^{\Delta L i b o r} \times$ Post $\times$ Sanc & & & & & $\begin{array}{l}-0.050 \\
(-1.169)\end{array}$ \\
\hline$\beta^{\Delta L i b o r} \times$ Post $\times$ Non - Sanc & & & & & $\begin{array}{c}0.035 \\
(1.379)\end{array}$ \\
\hline$\beta^{S u b}$ & $\begin{array}{l}-0.011 \\
(-1.535)\end{array}$ & $\begin{array}{l}-0.011 \\
(-1.545)\end{array}$ & $\begin{array}{l}-0.011 \\
(-1.562)\end{array}$ & $\begin{array}{l}-0.011 \\
(-1.539)\end{array}$ & $\begin{array}{c}-0.012 \\
(-1.592)\end{array}$ \\
\hline$\beta^{M k t}$ & $\begin{array}{c}0.055^{* * *} \\
(3.602)\end{array}$ & $\begin{array}{c}0.054^{* * *} \\
(3.552)\end{array}$ & $\begin{array}{c}0.055^{* * *} \\
(3.603)\end{array}$ & $\begin{array}{c}0.055^{* * *} \\
(3.578)\end{array}$ & $\begin{array}{c}0.054^{* * *} \\
(3.568)\end{array}$ \\
\hline$\beta^{V I X}$ & $\begin{array}{c}0.012 \\
(0.912)\end{array}$ & $\begin{array}{c}0.012 \\
(0.896)\end{array}$ & $\begin{array}{c}0.012 \\
(0.907)\end{array}$ & $\begin{array}{c}0.012 \\
(0.946)\end{array}$ & $\begin{array}{c}0.012 \\
(0.958)\end{array}$ \\
\hline Size & $\begin{array}{c}-0.158^{* * *} \\
(-7.988)\end{array}$ & $\begin{array}{c}-0.159 * * * \\
(-7.966)\end{array}$ & $\begin{array}{c}-0.158^{* * *} \\
(-7.996)\end{array}$ & $\begin{array}{c}-0.157^{* * *} \\
(-7.906)\end{array}$ & $\begin{array}{c}-0.158^{* * *} \\
(-8.038)\end{array}$ \\
\hline Yield & $\begin{array}{c}0.151^{* * *} \\
(6.583)\end{array}$ & $\begin{array}{c}0.154^{* * *} \\
(6.659)\end{array}$ & $\begin{array}{c}0.151^{* * *} \\
(6.573)\end{array}$ & $\begin{array}{c}0.153^{* * *} \\
(6.642)\end{array}$ & $\begin{array}{c}0.151^{* * *} \\
(6.605)\end{array}$ \\
\hline Vol & $\begin{array}{c}0.033^{* *} \\
(2.447)\end{array}$ & $\begin{array}{c}0.033^{* *} \\
(2.466)\end{array}$ & $\begin{array}{c}0.033^{* *} \\
(2.448)\end{array}$ & $\begin{array}{c}0.034^{* *} \\
(2.497)\end{array}$ & $\begin{array}{l}0.032^{* *} \\
(2.415)\end{array}$ \\
\hline $\begin{array}{l}\text { Obs. } \\
R^{2}\end{array}$ & $\begin{array}{c}20,745 \\
0.026\end{array}$ & $\begin{array}{c}20,745 \\
0.026\end{array}$ & $\begin{array}{c}20,745 \\
0.026\end{array}$ & $\begin{array}{c}20,745 \\
0.026\end{array}$ & $\begin{array}{c}20,745 \\
0.026\end{array}$ \\
\hline
\end{tabular}




\section{Table 5: Estimated gains from Libor manipulation}

This table reports estimated gains from Libor manipulation for the period from 1999 through 2010. Gains are computed for the cash flow hypothesis using the procedure outlined in Section 4.3. Columns (1) through (3) correspond to the results reported in columns (1), (2), and (4) in Table 4. Total gains are computed summing across all banks and currency-maturity pairs. US is defined as one for panel banks incorporated in the U.S., and zero otherwise. Non-US is defined as 1-US. Sanc is defined as one for the five panel banks that have been among the first to be investigated and also received the largest fines, and zero otherwise. Non-Sanc is defined as 1-Sanc. In parentheses, below the estimated coefficients, are the $t$-statistics for the average weekly gains. Statistical significance at the $1 \%, 5 \%$, and $10 \%$ is denoted by three, two, and one asterisks, respectively. Units are millions USD.

\begin{tabular}{lccc}
\hline \hline & $(1)$ & $(2)$ & $(3)$ \\
\hline Total gains & $\$ 29,319^{* * *}$ & & \\
& $(5.260)$ & $\$ 8,369^{* * *}$ & \\
US & & $(3.985)$ & \\
& & $\$ 26,440^{* * *}$ & \\
Non-US & & $(5.923)$ & $\$ 13,921^{* * *}$ \\
& & $(5.391)$ \\
Sanc & & $\$ 20,161^{* * *}$ \\
& & & $(5.214)$ \\
Non-Sanc & & \\
& & & \\
& & & \\
\hline \hline
\end{tabular}




\section{Table 6: Syndicated loans and Libor exposure}

This table reports results for the regression in Eq. (4), where we regress bank excess returns on the changes in Libor $(\Delta$ Libor $)$, the log ratio of the outstanding amount of syndicated loans to the bank's equity market capitalization (Synd), the interaction between $\Delta$ Libor and Synd, and control variables. Variables $\Delta$ Libor and Synd are for matching currencymaturity pairs. Control variables include market excess returns $\left(r_{M k t}-r_{f}\right)$ and changes in VIX ( $\left.\Delta V I X\right)$. Column (1) pools information across currencies. Columns (2) and (3) report results separately for the USD and GBP. In parentheses, below the estimated coefficients, are the $t$-statistics clustered by month. Statistical significance at the $1 \%, 5 \%$, and $10 \%$ is denoted by three, two, and one asterisks, respectively. The period is from January 2000 through November 2012.

\begin{tabular}{lccc}
\hline \hline & & & \\
& $(1)$ & $(2)$ & $(3)$ \\
& Pooled & USD & GBP \\
\hline$\Delta$ Libor & 0.010 & 0.009 & 0.005 \\
Synd & $(0.652)$ & $(0.570)$ & $(0.366)$ \\
& -0.000 & -0.000 & -0.001 \\
$\Delta$ Libor $\times$ Synd & $(-0.686)$ & $(-0.756)$ & $(-1.504)$ \\
& $0.002^{* *}$ & $0.003^{* *}$ & 0.006 \\
$r_{M k t}-r_{f}$ & $(2.110)$ & $(2.126)$ & $(1.501)$ \\
& $1.477^{* * *}$ & $1.442^{* * *}$ & $1.459^{* * *}$ \\
$\Delta V I X$ & $(16.254)$ & $(17.038)$ & $(15.811)$ \\
& -0.001 & -0.001 & -0.001 \\
& $(-1.178)$ & $(-1.326)$ & $(-1.461)$ \\
Obs. & & & \\
adj. $R^{2}$ & 36,948 & 14,940 & 10,793 \\
& 0.510 & 0.513 & 0.507 \\
\hline \hline
\end{tabular}


Table 7: Balance sheet data and Libor exposure

This table reports results for the quarterly regression in Eq. (6), where we regress the sensitivity of bank excess returns to changes in Libor $\left(\beta^{\Delta L i b o r}\right)$ on Libor exposure computed from Call Reports balance sheet data $(B S E)$. The regression is estimated by pooling observations for five banks with substantial operations in the U.S. covered by the Call Reports data. The BSE is computed at the end of each quarter according to Eq. (5) and $\beta^{\Delta L i b o r}$ is the quarterly average of weekly observations from regression in Eq. (1). All the Libor exposures are for the USD Libor. Columns (1) through (3) present results for the 1,3, and 6-month maturity. In column (4), both measures of Libor exposure are averaged across the maturities. The coefficients are multiplied by 100 and expressed in percentages. In parentheses, below the estimated coefficients, are the $t$-statistics clustered by quarter. Statistical significance at the $1 \%, 5 \%$, and $10 \%$ is denoted by three, two, and one asterisks, respectively. The period is from January 1999 through November 2012.

\begin{tabular}{lcccc}
\hline \hline & & & & \\
& $(1)$ & $(2)$ & $(3)$ & $(4)$ \\
& 1-month & 3 -month & 6 -month & Average \\
\hline BSE & $0.026^{* * *}$ & $0.064^{*}$ & $0.036^{*}$ & $0.119^{* *}$ \\
& $(3.314)$ & $(1.691)$ & $(1.735)$ & $(2.247)$ \\
& & & & \\
Obs. & 214 & 214 & 214 & 214 \\
adj. $R^{2}$ & 0.045 & 0.057 & 0.007 & 0.037 \\
& & & & \\
\hline \hline
\end{tabular}




\section{Table 8: Robustness analysis}

This table reports various specifications of results for the prosecution hypothesis corresponding to column (1) in Table 4 . Panel A reports the following specifications: in columns (1) and (2), results include respectively the absolute value and the squared value of $\beta^{\Delta L i b o r}$ as additional control variables; in columns (3) and (4), results include as additional control variables the sensitivity to changes in the OIS rate and the sensitivity to the term spread (both estimated as additional regressors in Stage 1 regression), respectively; in column (5), changes in Libor are instrumented with the changes in the corresponding risk-free (and market excess returns and changes in VIX). Panel B reports results, where the Stage 1 sensitivities are estimated on a rolling window size from 20- to 45-weeks in steps of 5 weeks. Panel C reports results for other robustness analyses: in column (1), results are based on weekly data; in column (2), the stage 1 regression excludes VIX; in columns (3) and (4), Pre is defined as one for the period through September 2010 and through March 2011, and zero otherwise; in column (5), the stage 1 sensitivities are estimated using local currency denominated returns; in column (6), results include the 1-year CDS as an additional control variable. All regressions include bank and time fixed effects within each currencymaturity pair, and the following unreported controls: $\beta^{S u b}, \beta^{M k t}, \beta^{V I X}$, Size, Yield, and Vol. In parentheses, below the estimated coefficients, are the $t$-statistics based on robust standard errors clustered by month. Statistical significance at the $1 \%, 5 \%$, and $10 \%$ is denoted by three, two, and one asterisks, respectively. The $R^{2}$ is from the regression of the residuals of the dependent and independent variables on the fixed effects. The sample contains monthly observations from July 1999 through November 2012.

Panel A: Interest-rate risk and endogeneity

\begin{tabular}{|c|c|c|c|c|c|}
\hline & $\begin{array}{c}(1) \\
\left|\beta^{\Delta L i b o r}\right|\end{array}$ & $\begin{array}{c}(2) \\
\left(\beta^{\Delta L i b o r}\right)^{2}\end{array}$ & $\begin{array}{l}(3) \\
\text { OIS }\end{array}$ & $\begin{array}{c}(4) \\
\text { TSPR }\end{array}$ & $\begin{array}{c}(5) \\
\text { TSLS }\end{array}$ \\
\hline$\beta^{\Delta L i b o r} \times$ Pre & $\begin{array}{c}0.031^{* * *} \\
(2.817)\end{array}$ & $\begin{array}{c}0.032^{* * *} \\
(2.837)\end{array}$ & $\begin{array}{c}0.024^{* *} \\
(2.210)\end{array}$ & $\begin{array}{c}0.036^{* * *} \\
(3.290)\end{array}$ & $\begin{array}{c}0.021^{* *} \\
(2.156)\end{array}$ \\
\hline$\beta^{\Delta L i b o r} \times$ Post & $\begin{array}{c}-0.006 \\
(-0.236)\end{array}$ & $\begin{array}{c}-0.006 \\
(-0.230)\end{array}$ & $\begin{array}{c}-0.015 \\
(-0.534)\end{array}$ & $\begin{array}{c}-0.015 \\
(-0.588)\end{array}$ & $\begin{array}{l}-0.004 \\
(-0.204)\end{array}$ \\
\hline$\left|\beta^{\Delta L i b o r}\right|$ & $\begin{array}{c}-0.000 \\
(-0.010)\end{array}$ & & & & \\
\hline$\left(\beta^{\Delta L i b o r}\right)^{2}$ & & $\begin{array}{c}-0.002 \\
(-0.419)\end{array}$ & & & \\
\hline$\beta^{\Delta O I S}$ & & & $\begin{array}{l}0.000^{*} \\
(1.777)\end{array}$ & & \\
\hline$\beta^{\triangle T S P R}$ & & & & $\begin{array}{c}-0.007 \\
(-0.600)\end{array}$ & \\
\hline $\begin{array}{l}\text { Obs. } \\
R^{2}\end{array}$ & $\begin{array}{c}20,745 \\
0.026\end{array}$ & $\begin{array}{c}20,745 \\
0.026\end{array}$ & $\begin{array}{c}20,745 \\
0.024\end{array}$ & $\begin{array}{c}20,745 \\
0.025\end{array}$ & $\begin{array}{c}20,536 \\
0.025\end{array}$ \\
\hline
\end{tabular}

Panel B: Length of the rolling window size (Stage 1, in weeks)

\begin{tabular}{lcccccc} 
Control & 20 & 25 & 30 & 35 & 40 & 45 \\
\hline$\beta^{\Delta \text { Libor }} \times$ Pre & $0.018^{*}$ & $0.026^{* *}$ & $0.032^{* * *}$ & $0.040^{* * *}$ & $0.037^{* * *}$ & $0.039^{* * *}$ \\
$\beta^{\Delta \text { Libor }} \times$ Post & $(1.700)$ & $(2.355)$ & $(2.943)$ & $(3.749)$ & $(3.517)$ & $(3.736)$ \\
& -0.005 & -0.008 & -0.009 & -0.018 & -0.012 & 0.002 \\
& $(-0.179)$ & $(-0.290)$ & $(-0.347)$ & $(-0.731)$ & $(-0.464)$ & $(0.067)$ \\
Obs. & & & & & & \\
$R^{2}$ & 20,910 & 20,805 & 20,651 & 20,524 & 20,373 & 20,240 \\
& 0.022 & 0.025 & 0.026 & 0.028 & 0.029 & 0.031
\end{tabular}

Panel C: Other robustness analysis

\begin{tabular}{lcccccc} 
& $(1)$ & $(2)$ & $(3)$ & $(4)$ & $(5)$ & $(6)$ \\
Control & Weekly & No VIX & Pre Sep2010 & Pre Mar2011 & Local currency & CDS \\
\hline$\beta^{\Delta \text { Libor }} \times$ Pre & $0.022^{* * *}$ & $0.023^{* *}$ & $0.034^{* * *}$ & $0.030^{* * *}$ & $0.034^{* * *}$ & $0.030^{* *}$ \\
$\beta^{\Delta \text { Libor }} \times$ Post & $(4.032)$ & $(2.157)$ & $(3.029)$ & $(2.789)$ & $(3.195)$ & $(2.376)$ \\
& -0.009 & -0.009 & -0.013 & -0.003 & -0.020 & -0.008 \\
CDS & $(-0.695)$ & $(-0.358)$ & $(-0.534)$ & $(-0.107)$ & $(-0.764)$ & $(-0.343)$ \\
& & & & & & $0.094^{* * *}$ \\
& & & & & & $(7.287)$ \\
Obs. & & & & & \\
$R^{2}$ & 90,581 & 20,759 & 20,745 & 20,745 & 20,745 & 17,771 \\
& 0.037 & 0.024 & 0.026 & 0.026 & 0.024 & 0.026 \\
\hline \hline
\end{tabular}


Figure 1: Time-series of Libor submissions

This figure plots weekly averages of panel banks' Libor submissions (solid line) with two standard deviation cross-sectional bands (dotted lines) for the four Libor rates: USD-3m (Panel A), GBP-6m (Panel B), JPY-6m (Panel C), and CHF-6m (Panel D). The sample contains weekly observations from January 1999 through November 2012.
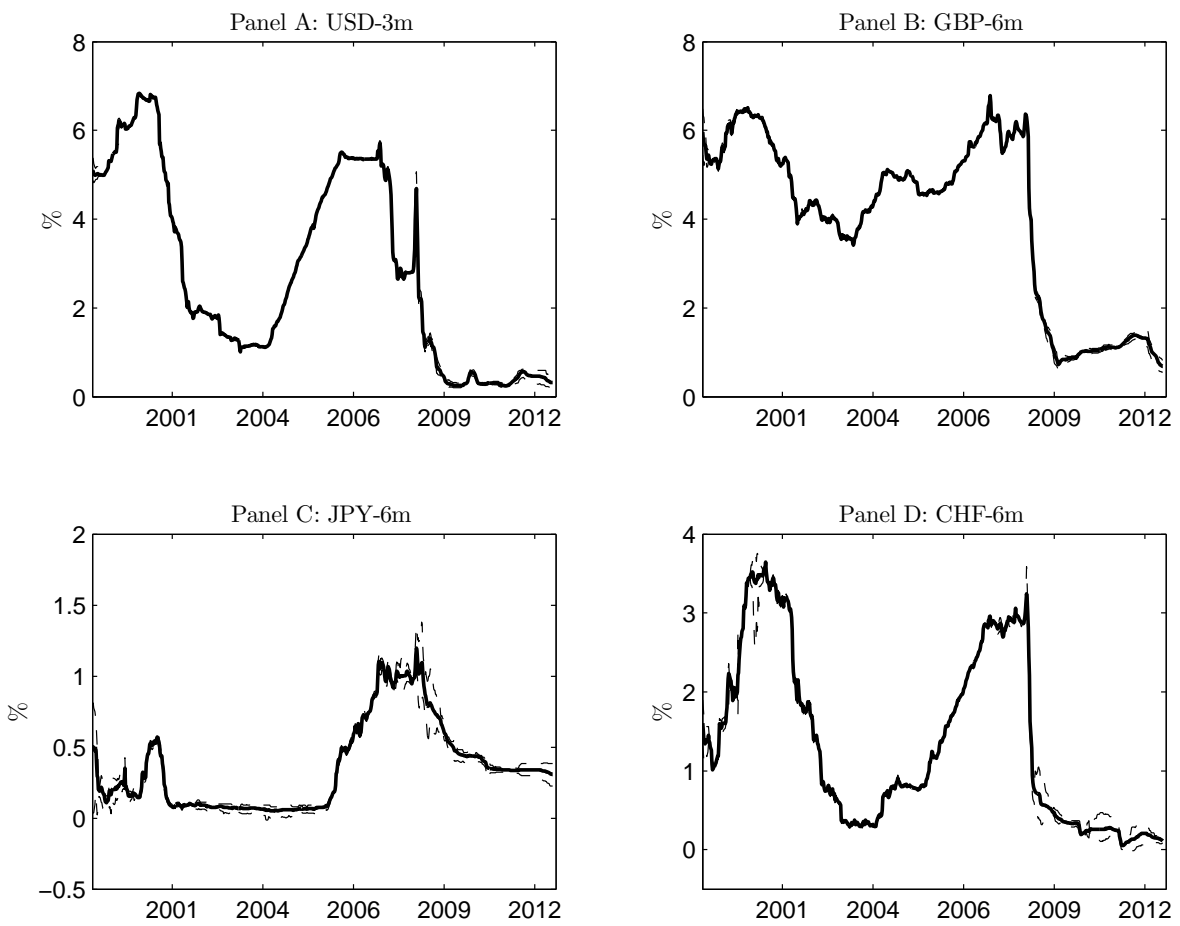
Figure 2: Cumulative distribution function (CDF) of sign change in Libor exposures

Panel A shows the fraction of Libor exposures from our Stage 1 regression that change sign within a given number of months. Panel B shows the same distribution based on the Call Report data (see Section 7.2).
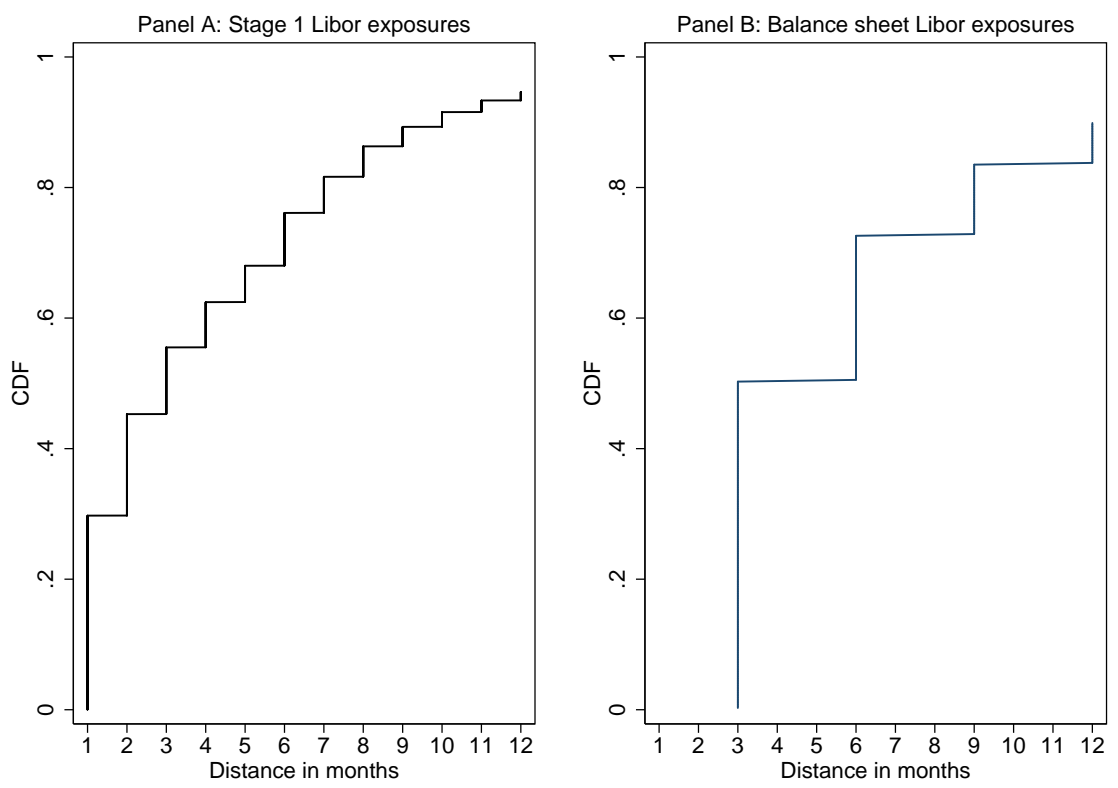


\section{Appendix}

\section{A Further details on Libor computation}

In this appendix, we provide details on Libor computation that have been in place throughout the period of our analysis, 1999 through 2012. During this time, the organization responsible for the computation of Libor is the British Bankers' Association (BBA), a trade association of over 200 banks based in London. The actual collection of the data and the computation of Libor is performed by Thomson Reuters. Libor is computed for 10 distinct currencies (the U.S. dollar, the Australian dollar, the British pound sterling, the Canadian dollar, the Danish krone, the Euro, the Japanese Yen, the New Zealand dollar, the Swedish krona, and the Swiss franc) and 15 different maturities. The 15 maturities range from overnight to one year.

While any bank that trades in London can apply to become a panel bank for any currency for which Libor is computed, the selection by BBA is based on three factors: (i) the scale of market activity, (ii) the reputation, and (iii) the perceived expertise of the bank. Thus, the number of panel banks varies with currencies and over time. However, within a given currency, the number of panel banks does not vary across maturities.

As described in Section 3.1, interest rate data from the panel banks are collected via a survey. The panel banks are supposed to report the lowest perceived interest rate at which the bank can borrow an unsecured, 'reasonable loan amount' in the London interbank market for a given currency and maturity. The maturity dates are standardized (International Swap Dealers Association (ISDA) norms). The definition of a 'reasonable loan amount' is not provided.

The Libor submissions are supposed to be reported by the bank's staff primarily responsible for its cash or liquidity management, via a secure computer application, to Thomson Reuters by 11:10am, London time. Thomson Reuters checks for data errors, allows the panel banks to correct obvious mistakes, and publishes Libor by 11:30am. At that time, Thomson Reuters also publicly releases the individual submissions provided by all the panel banks. If any errors are identified post publication, Thomson Reuters corrects these and publishes recomputed Libor and individual submissions by 12:00 noon, London time. Panel banks do not have access to individual submissions and cannot legally view other panel banks' submissions prior to the 
publication of the official Libor.

For computing the trimmed averages, the number of contributing banks is rounded down to the nearest number divisible by four. For example, for the USD with 18 panel banks the number of banks will be rounded off to 16 . No submissions are excluded at this stage. Thomson Reuters then excludes the $25 \%$ highest and lowest submissions of the rounded number. For the USD example cited above, this means Thomson Reuters will exclude the highest and lowest four (25\% of 16 ) submissions. The remaining 10 submissions are simply averaged to compute the Libor for USD for any given maturity.

\section{B List of panel banks by currency}

In this Appendix, we provide a list of panel banks for each of the four Libor currencies used in our main analysis, as of 2012:

USD: CS, UBS, RBC, BNP, CA, SG, DB, MITF, SMFI, BARC, HSBC, LLO, RBS, BOA, CITI, JPM, NOR*, RABO*

GBP: UBS, RBC, BNP, CA, SG, DB, MITF, MIZ, BS, BARC, HSBC, LLO, RBS

JPY: UBS, CA, SG, DB, MITF, MIZ, SMFI, BARC, HSBC, LLO, RBS, CITI, JPM, NOR*, RABO*

CHF: CS, UBS, SG, DB, MITF, BARC, HSBC, LLO, CITI, JPM, RABO*

Legend: CS - Credit Suisse Group, UBS - Union Bank of Switzerland, RBC - Royal Bank of Canada, BNP - BNP Paribas, CA - Credit Agricole, SG - Societe Generale, DB - Deutsche Bank, MITF - Bank of Tokyo-Mitsubishi UFJ Ltd., MIZ - Mizuho, SMFI - Sumitomo Mitsui Banking Corporation, BS - Banco Santander (replaced Abbey National), BARC - Barclays, HSBC - HSBC Hdg, LLO - Lloyds Banking Group, RBS - Royal Bank of Scotland Group, BOA

- Bank of America, CITI - Citigroup, JPM - JP Morgan Chase \& Co, NOR* - Norinchukin, RABO* - Rabobank.

* - denotes a privately held bank. 


\section{Summary statistics for the main variables}

Table C.1 reports summary statistics for the Libor (Panel A) and the corresponding panel banks' Libor submissions (Panel B). All rates are expressed in percentages (\%). Average cross-sectional standard deviations of submissions are between 2.3 and 4.1 basis points.

[Table C.1 about here]

Table C.2 reports summary statistics for bank equity returns and the control variables. Note that the correlation between realized volatility vol and credit default swaps $C D S$ is positive at 0.47. Correlations for the other control variables are generally much lower.

[Table C.2 about here]

\section{Call Report Data}

Table D.1 reports summary statistics for the balance sheet variables from the Call Report data and the resultant quarterly balance sheet USD Libor exposure (BSE) calculated in Eq. (5). The mean for the BSE across all five banks is negative for all maturities, which implies that the banks in our sample were short Libor over the sample period 1999-2012. Furthermore, the magnitude of the exposure is quite large, at around -12. This implies that the size of off-balance sheet derivatives for the banks in our sample far exceeds the size of total balance sheet assets. It also confirms that using Call Reports data is necessary in order to properly capture the net exposure of banks to interest rate movements. the standard deviation of the BSE is 15, which indicates that these banks were not always short Libor, but their exposures often changed sign over the sample period. Finally, the average $\operatorname{AR}(1)$ across $B S E$ measures is 0.30 , which is comparable to the persistence of our Stage 1 estimate for Libor exposure.

[Table D.1 about here] 


\section{Table C.1: Summary statistics for Libor and Libor submissions}

This table reports summary statistics for Libor (Panel A) and panel banks' Libor submissions (Panel B) for four currencies (USD, GBP, JPY, and CHF) and three maturities (1-, 3-, and 6-month). In Panel A, sd is the time-series standard deviation. In Panel B, csd is the average cross-sectional standard deviation of submissions. The sample contains daily observations from January 1999 through November 2012.

\begin{tabular}{|c|c|c|c|c|c|c|c|c|c|}
\hline \multirow[b]{2}{*}{ Currency-maturity } & \multicolumn{6}{|c|}{ Panel A: Libor fixing } & \multirow[b]{2}{*}{ p75 } & \multirow[b]{2}{*}{$\max$} & \multirow[b]{2}{*}{ skew } \\
\hline & $\mathrm{N}$ & mean & sd & $\min$ & p25 & p50 & & & \\
\hline USD-1m & 3515 & 2.693 & 2.166 & 0.185 & 0.347 & 2.016 & 4.958 & 6.821 & 0.341 \\
\hline USD-3m & 3515 & 2.810 & 2.143 & 0.245 & 0.629 & 2.163 & 5.030 & 6.869 & 0.347 \\
\hline USD-6m & 3515 & 2.943 & 2.086 & 0.383 & 1.110 & 2.321 & 5.062 & 7.109 & 0.363 \\
\hline GBP-1m & 3515 & 3.734 & 2.046 & 0.496 & 0.770 & 4.581 & 5.382 & 6.750 & -0.623 \\
\hline GBP-3m & 3515 & 3.875 & 1.999 & 0.523 & 1.256 & 4.590 & 5.475 & 6.904 & -0.594 \\
\hline GBP-6m & 3515 & 3.993 & 1.919 & 0.680 & 1.474 & 4.582 & 5.546 & 6.799 & -0.557 \\
\hline $\mathrm{JPY}-1 \mathrm{~m}$ & 3515 & 0.224 & 0.241 & 0.036 & 0.054 & 0.139 & 0.330 & 1.588 & 1.576 \\
\hline JPY-3m & 3515 & 0.286 & 0.281 & 0.046 & 0.068 & 0.194 & 0.412 & 1.094 & 1.294 \\
\hline JPY-6m & 3515 & 0.358 & 0.305 & 0.057 & 0.081 & 0.329 & 0.504 & 1.185 & 0.952 \\
\hline $\mathrm{CHF}-1 \mathrm{~m}$ & 3515 & 1.152 & 1.083 & -0.013 & 0.192 & 0.740 & 2.135 & 3.552 & 0.718 \\
\hline CHF-3m & 3515 & 1.263 & 1.118 & 0.003 & 0.257 & 0.770 & 2.210 & 3.590 & 0.648 \\
\hline CHF-6m & 3515 & 1.356 & 1.119 & 0.043 & 0.333 & 0.850 & 2.280 & 3.768 & 0.614 \\
\hline
\end{tabular}

Panel B: Libor submissions

\begin{tabular}{lccccccccc} 
Currency-maturity & $\mathrm{N}$ & $\mathrm{mean}$ & $\mathrm{csd}$ & $\mathrm{min}$ & $\mathrm{p} 25$ & $\mathrm{p} 50$ & $\mathrm{p} 75$ & $\max$ & skew \\
\hline USD-1m & 49164 & 2.514 & 0.023 & 0.110 & 0.300 & 1.840 & 4.900 & 6.890 & 0.449 \\
USD-3m & 49261 & 2.638 & 0.025 & 0.200 & 0.510 & 1.900 & 4.970 & 6.890 & 0.446 \\
USD-6m & 49155 & 2.770 & 0.028 & 0.300 & 0.770 & 2.060 & 4.950 & 7.130 & 0.464 \\
GBP-1m & 44102 & 3.472 & 0.025 & 0.400 & 0.670 & 4.130 & 5.270 & 6.930 & -0.401 \\
GBP-3m & 44116 & 3.619 & 0.027 & 0.450 & 0.980 & 4.230 & 5.313 & 6.930 & -0.381 \\
GBP-6m & 44115 & 3.749 & 0.029 & 0.550 & 1.275 & 4.410 & 5.344 & 6.850 & -0.354 \\
JPY-1m & 44565 & 0.233 & 0.041 & -0.060 & 0.060 & 0.140 & 0.340 & 2.000 & 1.529 \\
JPY-3m & 45114 & 0.296 & 0.024 & -0.060 & 0.070 & 0.190 & 0.420 & 1.350 & 1.246 \\
JPY-6m & 45113 & 0.373 & 0.027 & -0.030 & 0.090 & 0.330 & 0.530 & 1.430 & 0.882 \\
CHF-1m & 37603 & 1.078 & 0.041 & -0.250 & 0.150 & 0.730 & 2.060 & 4.950 & 0.790 \\
CHF-3m & 34721 & 1.199 & 0.031 & -0.150 & 0.250 & 0.750 & 2.150 & 5.230 & 0.703 \\
CHF-6m & 34721 & 1.292 & 0.034 & 0.010 & 0.320 & 0.810 & 2.180 & 5.430 & 0.668 \\
& & & & & & & & & \\
\hline \hline
\end{tabular}


Table C.2: Summary statistics for bank returns and control variables

This table reports summary statistics for panel bank equity returns $(r)$, domestic aggregate stock market returns $\left(r_{M k t}\right)$, changes in VIX $(\Delta V I X)$, banks' log market capitalization (Size), the 1-year domestic Treasury rate (Yield), the realized weekly volatility of banks' equity returns $(\mathrm{vol})$, and the 1-year CDS premium on banks' equity in bps $(C D S)$. The sample contains weekly observations from January 1999 through November 2012.

\begin{tabular}{|c|c|c|c|c|c|c|c|c|c|}
\hline \multicolumn{10}{|c|}{ Panel A: Summary statistics } \\
\hline & $\mathrm{N}$ & mean & sd & $\min$ & p25 & med & p75 & $\max$ & skew \\
\hline$r$ & 2,174 & 0.007 & 0.069 & -0.371 & -0.022 & 0.001 & 0.026 & 1.332 & 4.979 \\
\hline & 2,174 & 0.004 & 0.027 & -0.085 & -0.012 & 0.003 & 0.018 & 0.127 & 0.615 \\
\hline$\Delta V I X$ & 2,174 & -0.091 & 2.902 & -19.340 & -1.310 & 0.240 & 1.290 & 7.630 & -2.084 \\
\hline Size & 2,174 & 11.080 & 0.658 & 8.640 & 10.650 & 11.040 & 11.520 & 12.560 & -0.015 \\
\hline Yield & 2,174 & 2.149 & 1.807 & -0.297 & 0.545 & 1.450 & 3.711 & 6.410 & 0.606 \\
\hline Vol & 2,174 & 0.022 & 0.023 & 0.001 & 0.009 & 0.015 & 0.026 & 0.369 & 5.031 \\
\hline$C D S$ & 2,174 & 49.490 & 73.100 & 1.000 & 5.562 & 20.000 & 65.270 & 877.900 & 3.596 \\
\hline \multicolumn{10}{|c|}{ Panel B: Correlation matrix } \\
\hline & $r$ & $r_{m}$ & $\Delta V I X$ & Size & Yield & $\mathrm{Vol}$ & $C D S$ & & \\
\hline$r$ & 1 & & & & & & & & \\
\hline$r_{m}$ & 0.666 & 1 & & & & & & & \\
\hline$\Delta V I X$ & -0.411 & -0.483 & 1 & & & & & & \\
\hline Size & -0.088 & -0.014 & 0.079 & 1 & & & & & \\
\hline Yield & 0.003 & 0.050 & -0.049 & 0.359 & 1 & & & & \\
\hline Vol & 0.419 & 0.257 & -0.301 & -0.321 & -0.149 & 1 & & & \\
\hline$C D S$ & 0.137 & 0.099 & -0.104 & -0.307 & -0.306 & 0.472 & 1 & & \\
\hline
\end{tabular}


Table D.1: Summary statistics for balance sheet variables

This table reports summary statistics for balance sheet variables from Call Report data for five banks with significant operations in the U.S. (Bank of America, Citigroup, Deutsche Bank, HSBC, and JP Morgan Chase). TA is total assets, $T L$ is total liabilities, $T D$ is total debt, $I R D H$ is the notional value of interest rate derivatives used for hedging, and $I R D T$ is the notional value of interest rate derivatives used for trading. All these items are expressed in USD millions. $B S E_{1 m}$, $B S E_{3 m}$, and $B S E_{6 m}$ are the bank balance sheet Libor exposures, calculated separately for the 1-, 3-, and 6-month maturity USD Libor according to Eq. (5). The sample contains quarterly observations from 1999 through 2012.

\begin{tabular}{|c|c|c|c|c|c|c|c|c|c|}
\hline & $\mathrm{N}$ & mean & sd & $\min$ & $\mathrm{p} 25$ & p50 & p75 & $\max$ & skew \\
\hline$\overline{T A}$ & 214 & $\$ 1,075.67$ & $\$ 750.98$ & $\$ 52.08$ & $\$ 398.93$ & $\$ 861.03$ & $\$ 1,829.52$ & $\$ 2,370.59$ & 0.260 \\
\hline$T L$ & 214 & $\$ 199.79$ & $\$ 155.14$ & $\$ 0.08$ & $\$ 80.84$ & $\$ 167.03$ & $\$ 318.14$ & $\$ 549.80$ & 0.560 \\
\hline$T D$ & 214 & $\$ 56.82$ & $\$ 52.96$ & $\$ 0.00$ & $\$ 14.39$ & $\$ 36.65$ & $\$ 95.75$ & $\$ 249.86$ & 1.070 \\
\hline$I R D H$ & 214 & $\$ 234.05$ & $\$ 350.20$ & $\$ 0.00$ & $\$ 47.55$ & $\$ 96.13$ & $\$ 282.05$ & $\$ 2,080.69$ & 3.080 \\
\hline$I R D T$ & 214 & $\$ 22,101$ & $\$ 22,138$ & $\$ 10$ & $\$ 2,666$ & $\$ 13,492$ & $\$ 38,743$ & $\$ 77,816$ & 0.820 \\
\hline$B S E_{1 m}$ & 214 & -11.800 & 15.630 & -50.510 & -25.070 & -11.680 & 0.600 & 22.990 & -0.120 \\
\hline$B S E_{3 m}$ & 214 & -12.460 & 15.090 & -50.510 & -25.070 & -11.930 & -0.020 & 22.990 & -0.110 \\
\hline$B S E_{6 m}$ & 214 & -12.010 & 15.470 & -50.510 & -25.070 & -11.680 & 0.270 & 22.990 & -0.100 \\
\hline
\end{tabular}

